\title{
Acute effects of LSD on circulating steroid levels in healthy subjects
}

Petra Strajhar, ${ }^{a, 1}$ Yasmin Schmid, ${ }^{b, 1}$ Evangelia Liakoni,, ${ }^{b}$ Patrick C. Dolder, ${ }^{b, c}$ Katharina M. Rentsch, ${ }^{c}$ Denise V. Kratschmar, ${ }^{a}$ Alex Odermatt, ${ }^{a, 2, * \star}$ and Matthias E. Liechti ${ }^{\text {b, 2, * }}$

${ }^{1,2}$ These authors contributed equally (shared first authors ${ }^{1}$, shared corresponding authors ${ }^{2}$ )

a Division of Molecular and Systems Toxicology, Department of Pharmaceutical Sciences, University of Basel, Basel, Switzerland

${ }^{\mathrm{b}}$ Division of Clinical Pharmacology and Toxicology, Department of Biomedicine and Department of Clinical Research and 'Laboratory Medicine, University Hospital Basel, Basel, Switzerland

Address for correspondence *(clinical): Matthias E. Liechti, MD, Division of Clinical Pharmacology and Toxicology, University Hospital Basel, Hebelstrasse 2, Basel, CH-4031, Switzerland; E-mail: matthias.liechti@usb.ch; Phone: +4161328 68 68; Fax: +4161265 4560. ${ }^{* *}$ (biological): Division of Molecular and Systems Toxicology, Department of Pharmaceutical Sciences, University of Basel, Klingelbergstrasse 50, Basel, CH-4056, Switzerland; E-mail: alex.odermatt@unibas.ch; Phone: +416126715 30; Fax: +4161267 1515.

Running title: Effects of LSD on steroid hormones

Keywords: LSD, serotonin, steroid, glucocorticoid

Word counts: abstract 249, introduction 671, discussion 1654

References: 57, Figures: 3, Table: 1, Supplement online: 1 


\section{ABSTRACT}

Lysergic acid diethylamide (LSD) is a serotonin 5-hydroxytryptamine-2A $\left(5-\mathrm{HT}_{2 \mathrm{~A}}\right)$ receptor agonist that is used recreationally worldwide. Interest in LSD research in humans waned after the 1970s, but the use of LSD in psychiatric research and practice has recently gained increasing attention. LSD produces pronounced acute psychedelic effects, but its influence on plasma steroid levels over time have not yet been characterized in humans. The effects of LSD $(200 \mu \mathrm{g})$ or placebo on plasma steroid levels were investigated in 16 healthy subjects using a randomized, double-blind, placebo-controlled cross-over study design. Plasma concentrationtime profiles were determined for 15 steroids using liquid-chromatography tandem massspectrometry. LSD increased plasma concentrations of the glucocorticoids cortisol, cortisone, corticosterone, and 11-dehydrocorticosterone compared with placebo. The mean maximum concentration of LSD was reached at $1.7 \mathrm{~h}$. Mean peak psychedelic effects were reached at $2.4 \mathrm{~h}$, with significant alterations in mental state from $0.5 \mathrm{~h}$ to $>10 \mathrm{~h}$. Mean maximal concentrations of cortisol and corticosterone were reached at $2.5 \mathrm{~h}$ and $1.9 \mathrm{~h}$, and significant elevations were observed $1.5-6 \mathrm{~h}$ and $1-3 \mathrm{~h}$ after drug administration, respectively. LSD also significantly increased plasma concentrations of the androgen dehydroepiandrosterone but not other androgens, progestogens, or mineralocorticoids compared with placebo. A close relationship was found between plasma LSD concentrations and changes in plasma cortisol and corticosterone and the psychotropic response to LSD, and no clockwise hysteresis was observed. In conclusion, LSD produces significant acute effects on circulating steroids, especially glucocorticoids. LSD-induced changes in circulating glucocorticoids were associated with plasma LSD concentrations over time and showed no acute pharmacological tolerance. 


\section{INTRODUCTION}

Lysergic acid diethylamide (LSD) was discovered in 1943 and is the prototypic serotonergic hallucinogen $(1,2)$. LSD was used in psychiatric research in the 1950 s to 1970 s to study psychotic-like states (i.e., model psychosis) and as an adjunct to psychotherapy (1) before its widespread recreational use. Today, LSD is still frequently used for personal and spiritual purposes. Additionally, renewed interest has been seen in the use of LSD in psychiatric research (3) and practice (4). Pharmacologically, LSD mainly acts as an agonist at serotonin 5hydroxytryptamine-1 $\left(5-\mathrm{HT}_{1}\right)$ and $5-\mathrm{HT}_{2}$ receptors, but it also interacts with dopamine $\mathrm{D}_{1}, \mathrm{D}_{2}$, and $D_{3}$ receptors and adrenergic $\alpha_{1}$ receptors (2). In contrast to such stimulants as amphetamines or cocaine, LSD does not interact with monoamine transporters (2). In humans, LSD induces alterations in perception, methylenedioxymethamphetamine (MDMA)-like empathogenic mood effects, and moderate sympathomimetic stimulation (3).

Many psychoactive substances activate the hypothalamic-pituitary-adrenal (HPA) axis, leading to the release of adrenocorticotropic hormone (ACTH) and glucocorticoids $(5,6)$. However, limited data have been reported on the effects of LSD on the HPA axis. In rats, LSD increased 17-hydroxy-ketosteroid and 17-ketosteroid levels in urine, consistent with HPA axis activation (7), but effects on circulating corticosterone could not be shown (8). LSD was reported to increase cortisol levels in zebrafish (9). Early studies in humans found that LSD increased 17-ketosteroid excretion in urine $(10,11)$, but effects on circulating steroid levels were not investigated. LSD also blunted the normal increase in 17-ketosteroid after ACTH administration (10). We recently found that LSD significantly increased plasma cortisol 180 min after LSD administration in humans (3), also consistent with HPA axis activation. However, a more comprehensive analysis of the effects of LSD on circulating levels of different steroids and its time course is still missing. 
Corticosteroids, androgens, and progestogens may all contribute to or modulate psychotropic drug actions $(12,13)$. For example, amphetamine or MDMA-induced increases in plasma cortisol levels were associated with subjective drug effects $(14,15)$, and stress-induced increases in plasma cortisol levels correlated with euphoric responses to amphetamine (16). Testosterone plays a role in social behavior (17) that is enhanced by MDMA (18). Testosterone and progesterone both reduced cocaine self-administration in female rhesus monkeys (19), and progesterone is known to be associated with reductions of subjective responses to and the use of psychostimulants in women $(13,20,21)$. Plasma dehydroepiandrosterone (DHEA) levels correlated with the subjective response to MDMA (14). Increases in DHEA and progesterone were also observed after $\gamma$-hydroxybutyrate administration (22).

Glucocorticoids are involved in the stress response and the modulation of behavior. In humans, inactive cortisone and active cortisol are the main glucocorticoids (23). Inactive 11dehydrocorticostrone and active corticosterone (i.e., the major glucocorticoids in rodents) are present at lower concentrations than cortisone and cortisol in human plasma. However, corticosterone, which also has additional mineralocorticoid properties, presents a higher brain/plasma concentration ratio than cortisol (24). Mineralocorticoids are involved in the regulation of sodium absorption and blood pressure (25), and they also play a role in modulating the immune response (26). 11-Deoxycortisol is a precursor of cortisol (27). Aldosterone is the most important mineralocorticoid. 11-Deoxycorticosterone is a precursor of corticosterone and aldosterone and has mineralocorticoid activity (28).

To characterize the influence of LSD on plasma steroid levels, we evaluated the acute effects of LSD on the plasma concentrations of a series of steroids over $24 \mathrm{~h}$ in healthy subjects. We also explored the effects of LSD on a wide range of other steroids. The plasma LSD concentration-steroid effect response curves over time were also plotted and compared with the LSD exposure-psychotropic effect relationship. 


\section{MATERIALS AND METHODS}

\section{Study design}

The study used a double-blind, placebo-controlled, cross-over design with two experimental test sessions in balanced order. The washout periods between sessions were at least 7 days. The study was conducted in accordance with the Declaration of Helsinki and International Conference on Harmonization Guidelines in Good Clinical Practice and approved by the Ethics Committee of the Canton of Basel, Switzerland, and Swiss Agency for Therapeutic Products (Swissmedic). The administration of LSD to healthy subjects was authorized by the Swiss Federal Office for Public Health, Bern, Switzerland. The study was registered at ClinicalTrials.gov (NCT01878942). All of the subjects provided written informed consent after being given written and oral descriptions of the study, the procedures involved, and the effects and possible risks of LSD administration.

\section{Participants}

Sixteen healthy subjects (eight men and eight women; mean age \pm SD: $28.6 \pm 6.2$ years; range: $25-51$ years) were included. The exclusion criteria were pregnancy, personal or family (first-degree relative) history of psychotic or major affective disorder, regular use of medications, chronic or acute physical illness, lifetime prevalence of illicit drug use $>10$ times (except for tetrahydrocannabinol), illicit drug use within the last 2 months, and illicit drug use during the study as reported in detail elsewhere (3). The subjects were asked to abstain from excessive alcohol consumption between test sessions and particularly limit their use to one drink on the day before the test sessions. Additionally, the participants were not allowed to drink caffeinecontaining liquids after midnight before the study day. Three subjects were light smokers $(<10$ cigarettes/day) and were told to maintain their usual smoking habits but not smoke during the 
sessions. We performed urine drug tests at screening and before each test session using TRIAGE 8 (Biosite, San Diego, CA, USA). The safety recommendations for high-dose hallucinogen research were followed (29).

\section{Study procedures}

The test sessions began at 8:00 AM. A urine sample was taken to verify abstinence from drugs of abuse, and a pregnancy test was performed in women. An indwelling intravenous catheter was placed in an antecubital vein for blood sampling, and the subjects completed baseline measurements. A single dose of LSD $(200 \mu \mathrm{g})$ or placebo was administered orally at 9:00 AM. A standardized lunch and dinner were served at 1:30 PM and 5:30 PM, respectively. The subjects were sent home the next day at 9:30 AM after the $24 \mathrm{~h}$ blood sample collection. The sessions were conducted in a calm laboratory environment. The subjects did not engage in any physical activity and were resting in hospital beds during the test session. Blood samples for the analysis of plasma steroid hormone levels were collected in lithium heparin tubes $1 \mathrm{~h}$ before and $0.5,1,1.5,2,2.5,3,4,6,8,10$, and $24 \mathrm{~h}$ after LSD or placebo administration. Blood samples were immediately centrifuged, and plasma was rapidly stored at $-20^{\circ} \mathrm{C}$. Plasma LSD concentrations were determined using liquid-chromatography tandem mass-spectrometry (LCMS/MS; (30). The pharmacokinetics of LSD have been reported previously (31), and LSD concentrations are included herein to describe the LSD exposure-steroid response effect relationship. The subjective and autonomic effects of LSD were also recorded in this study and have been reported previously (3). The subjective effects of LSD over time were repeatedly recorded at the times of blood sampling using visual analog scales (VAS) as previously reported $(3,31)$ and are also presented herein for comparisons with the effects of LSD on steroid concentrations (Fig. 3 and Fig. S1). VASs included "any drug effects", "good drug effects", "bad drug effects", "fear", and "stimulation". VASs were presented as 100-mm horizontal lines (0$100 \%)$ marked "not at all" on the left and "extremely" on the right $(3,32)$. 


\section{Steroid quantification}

Plasma steroid hormone levels (cortisol, cortisone, corticosterone, 11 dehydrocorticosterone, 11-deoxycorticosterone, aldosterone, DHEA, DHEA sulfate [DHEAS], $\Delta 4$-androstene-3,17-dione [androstenedione], testosterone, 11-deoxycortisol, progesterone, 5adihydrotestosterone, androsterone, and 17a-hydroxyprogesterone) were determined as previously described with minor adaptations (6). A detailed description of the materials, procedure, and method validation is included in the Supplemental Data.

Briefly, for solid-phase extraction, $700 \mu \mathrm{l}$ of each plasma sample was mixed with $100 \mu \mathrm{l}$ of protein precipitation solution ( $0.8 \mathrm{M}$ zinc sulfate in water/methanol $[50 / 50, \mathrm{v} / \mathrm{v}])$ that contained deuterium-labeled aldosterone, corticosterone, androstenedione, androsterone, $5 a-$ dihydrotestosterone, and testosterone as internal standards and diluted to a final volume of $1 \mathrm{ml}$ with water. The samples were incubated in a thermoshaker for 10 min at $4^{\circ} \mathrm{C}$ with thorough shaking (1300 rotations per minute). The samples were then centrifuged for 10 min at $16,000 \times$ relative centrifugal force at $4^{\circ} \mathrm{C}$, and $700 \mu \mathrm{l}$ of the supernatants was transferred to Oasis $\mathrm{HBL}$ SPE cartridges, preconditioned with methanol and water. After washing once with $1 \mathrm{ml}$ of water and twice with $1 \mathrm{ml}$ of methanol/water $(10 / 90, \mathrm{v} / \mathrm{v})$, the steroids were eluted with $1 \mathrm{ml}$ of methanol and evaporated to dryness. The samples were then reconstituted in $25 \mu$ of methanol. The steroids were separated and quantified by ultra-pressure LC-MS/MS (UPLC-MS/MS) using an Agilent 1290 UPLC coupled to an Agilent 6490 triple quadrupole mass spectrometer equipped with a jet-stream electrospray ionization interface. Analyte separation was achieved using a reverse-phase column (Waters ACQUITY UPLC BEH C18, $1.7 \mu \mathrm{m}, 2.1 \times 150 \mathrm{~mm}$ ). Mass Hunter software (Agilent Technologies) was used for data acquisition and analysis. As described in detail in the supplement, the variation coefficient was $<15 \%$ and accuracy between 85 and $115 \%$ tested at three concentrations for all analytes. The recovery of control samples 
was in the range of $80-120 \%$.

\section{Drugs}

Gelatin capsules that contained $100 \mu \mathrm{g}$ LSD (D-lysergic acid diethylamide hydrate; Lipomed AG, Arlesheim, Switzerland) and corresponding placebo capsules were prepared with authorization from the Swiss Federal Office for Public Health. LSD was administered in a single absolute dose of $200 \mu \mathrm{g}$, corresponding to a dose of $2.8 \pm 0.1 \mathrm{mg} / \mathrm{kg}$ body weight (mean \pm SEM). The same dose was previously used in LSD-assisted psychotherapy in a clinical study (4). The dose was in the upper range of doses that are taken for recreational purposes and expected to induce robust effects in humans (1).

\section{Statistical analyses}

To determine differences between LSD and placebo, maximum concentration $\left(\mathrm{C}_{\max }\right)$ values and areas under the concentration-time curve (AUCs) were compared for each steroid using repeated-measures analysis of variance (ANOVA), with drug (LSD vs. placebo) as the within-subject factor. Gender differences were determined by including gender (male vs. female) as a between-subject factor in the ANOVA. To test how long the subjective, cortisol, and corticosterone responses last over time, data were also analyzed using two-way ANOVAs with drug and time as factors and Tukey tests were used for post hoc comparisons between corresponding time points. $\mathrm{C}_{\max }$ was determined directly from the concentration-time curves. AUC values were determined from time $0.5 \mathrm{~h}$ to $10 \mathrm{~h}\left(\mathrm{AUC}_{10}\right)$ using the trapezoidal method. The LSD exposure-steroid concentration response relationships were explored by plotting the LSD response as a function of steroid concentration after LSD administration minus the individual time-matched concentration after placebo as a function of LSD plasma concentrations at each time point (hysteresis curves). Correlations between mean LSD concentrations and mean LSD- 
induced subjective (5 scales) or endocrine responses (cortisol and corticosterone) over time as well as correlations between subjective and endocrine responses over time ( $n=12$ time points) within the 16 subjects were then analyzed using Spearman's rank correlations. The level of significance was set to $P<0.05$. Seventeen correlations were tested, giving a Bonferronicorrected statistical threshold of $\mathrm{P}<0.003$. The statistical analyses were performed using STATISTICA 12 software (StatSoft, Tulsa, OK, USA).

\section{RESULTS}

The plasma concentration-time curves of the different steroid hormones after LSD and placebo administration are shown in Fig. 1 and 2. Peak steroid concentrations, total steroid exposure over time ( $A \cup C_{10}$ values), and statistics are presented in Table 1. LSD significantly increased the plasma concentrations of the glucocorticoids cortisol, cortisone, corticosterone, and 11-dehydrocorticosterone compared with placebo (Fig. 1B-E). LSD also significantly increased the sums of cortisol+cortisone and corticosterone+11-dehydrocorticosterone and the cortisol/cortisone and corticosterone/11-dehydrocorticosterone ratios (Table 1), indicating elevated glucocorticoid production. LSD had no effect on plasma concentrations of the cortisol precursor 11-deoxycortisol (Fig. 1A), the mineralocorticoid aldosterone (Fig. 1G), or the moderate mineralocorticoid 11-deoxycorticosteone (Fig. 1F). LSD significantly increased plasma concentrations of DHEA compared with placebo (Fig. 2A) and also increased the plasma exposure $\left(\mathrm{AUC}_{10}\right.$ but not $\left.\mathrm{C}_{\max }\right)$ of androstenedione compared with placebo (Fig. $\left.2 \mathrm{C}\right)$. In contrast, LSD did not alter plasma concentrations of the androgens DHEAS (Fig. 2B), testosterone (Fig. 2D, F), 5a-dihydrotestosterone, or androsterone (Table 1). Similarly, LSD had no effect on plasma concentrations of the progestogens progesterone (Fig. 2G) and 17ahydroxyprogesterone (Fig. 2E). As expected, testosterone levels were higher in men than in women, but no sex differences in testosterone levels in response to LSD were found compared with placebo. Similarly, no other drug and gender interaction effects on any of the steroid levels 
were observed.

LSD exposure-steroid concentration response relationships are shown in Fig. 3. Pharmacokinetic data on LSD from the present study have been published elsewhere in detail (31). The $C_{\max }$ of LSD was reached $1.7 \pm 1 \mathrm{~h}$ (mean $\pm S D$ ) after LSD administration (Fig. 3A, B). The peak psychotropic effect was reached $2.4 \pm 0.8 \mathrm{~h}$, with significant alterations in mental state from 0.5 to $10 \mathrm{~h}$ after LSD administration (Fig. 3A, B). Maximum concentrations of cortisol (Fig. $3 \mathrm{C}, \mathrm{D}$ ) and corticosterone (Fig. 3E, F) were reached at $2.5 \pm 0.8 \mathrm{~h}$ and $1.9 \pm 0.5 \mathrm{~h}$ (mean $\pm \mathrm{SD}$ ), and significant elevations were observed 1.5-6 $\mathrm{h}$ and 1-3 $\mathrm{h}$ after LSD administration, respectively. Thus, plasma levels of corticosterone increased more rapidly and fell more rapidly back to baseline levels compared with cortisol levels (Fig. 3E, F). Counterclockwise hysteresis was observed for subjective "any drug effects" and cortisol, consistent with an initial delay between increases in plasma LSD concentration and drug effects that was attributable to drug absorption/distribution up to $2.5 \mathrm{~h}$ (Fig. 3B, D). After maximal drug effects were reached at 2.5 $\mathrm{h}$, the psychotropic effects and changes in plasma cortisol levels decreased slowly, paralleling the steady decrease in the plasma levels of LSD (Fig. 3A, C) and presenting a close concentration-effect relationship up to $24 \mathrm{~h}$ (Fig. 3B, D). The average plasma level of LSD was strongly correlated with the average subjective "any drug effects" and the average level of cortisol over time $\left(R_{S}=0.94, P<0.001\right.$ and $R_{S}=0.97, P<0.001$, respectively). The relationship between subjective "any drug effects" and circulating glucocorticoids was explored by plotting the LSD-induced subjective "any drug effects" as a function of changes in the plasma concentrations of cortisol and corticosterone (Fig. 3G, H). After LSD administration, subjective drug effects increased together with plasma corticosterone levels but more rapidly than plasma cortisol levels. At $1 \mathrm{~h}$ after LSD administration, $80 \%$ of the average maximal subjective drug effect was reached, with more than $50 \%$ of the maximal corticosterone response but less than $50 \%$ of the maximal cortisol response. Thus, the psychotropic effects of LSD seemed to appear faster than the LSD-induced changes in plasma cortisol levels. Nevertheless, the average 
subjective "any drug effect" was closely related to the levels of cortisol and corticosterone $\left(R_{s}=0.97, P<0.001\right.$ and $R_{s}=0.90, P<0.001$, respectively). LSD produced pronounced subjective "good drug effects" and "stimulation", but induced only small increases in subjective "bad drug effects" and "fear" compared with placebo as reported previously (3). Average subjective "good drug effects" and "stimulation" were both strongly associated with the plasma levels of LSD over time $\left(R_{s}=0.88, P<0.001\right.$ and $R_{s}=0.84, P<0.001$, respectively). Average "good drug effects" and "stimulation" were both also associated with the plasma levels of cortisol $\left(R_{s}=0.93, P<0.001\right.$ and $R_{s}=0.82, P<0.001$, respectively $)$ and corticosterone $\left(R_{s}=0.86, P<0.001\right.$ and $R_{s}=0.84, P<0.001$, respectively). In contrast, LSD-induced "bad drug effects" or "fear" did not correlate with LSDinduced increases in cortisol or corticosterone over time. Supplemental Fig. S1 shows the concentration-effect curves of MDMA (125 mg) for "any drug effects", cortisol, and corticosterone based on our previous study in 16 healthy subjects $(6,33)$ for comparisons with the concentration-effect curves of LSD (Fig. 3B, D, F). The MDMA concentration-effect relationships for the psychotropic effects and glucocorticoid responses exhibited clockwise hysteresis, indicating acute pharmacological tolerance (Supplemental Fig. S1A-C). Consistently, the average subjective "any drug effects" did not significantly correlate with the average plasma levels of MDMA over time. After MDMA administration, the subjective drug effects increased faster and particularly decreased faster than the plasma levels of cortisol (Supplemental Fig. S1D) and corticosterone (Supplemental Fig. S1E; i.e., clockwise hysteresis). Thus, MDMAinduced changes in plasma glucocorticoid levels over time did not well reflect the psychotropic effects of the drug, in contrast to LSD, in which no tolerance was observed.

\section{DISCUSSION}

The present study provided insights into the acute effects of LSD on the plasma levels of a series of steroids in healthy humans. LSD increased circulating glucocorticoid levels, whereby the levels of both inactive 11-dehydrocorticosterone and cortisone and active corticosterone and 
cortisol were elevated compared with placebo, indicating HPA axis stimulation. The LSDinduced changes in circulating cortisol and corticosterone had, in contrast to the glucocorticoid response to MDMA, a close relationship with both the plasma concentrations of LSD and psychotropic response to LSD. No clockwise hysteresis in the LSD concentration-effect plots was observed, thus indicating no acute tolerance to the effects of LSD on glucocorticoid concentrations or subjective drug effects, in contrast to the pronounced acute tolerance observed with MDMA. LSD also significantly increased plasma concentrations of the androgens DHEA $\left(A \cup C_{10}, C_{\max }\right)$ and androstenedione $\left(\mathrm{AUC}_{10}\right)$, but the concentration of testosterone was unaltered, and the ratio of active to inactive androgens (testosterone/androstenedione) decreased. Other androgens, as well as progestogens and mineralocorticoids, were unaffected by LSD.

The LSD-induced relative increase in corticosterone was greater than the increase in cortisol. The brain penetration of corticosterone is greater compared with cortisol because of differential transport by P-glycoprotein at the blood-brain barrier (24). Thus, the effect of LSD on brain corticosterone concentrations may be more prominent. Additionally, the LSD-induced changes in circulating corticosterone in the present study also more closely reflected psychotropic alterations over time, in which plasma cortisol levels increased later in time than the subjective effects of LSD after drug administration.

Stimulation of the HPA axis by LSD has previously been demonstrated in animals $(7,9)$ and humans (10). The present study in humans provided a more comprehensive analysis of plasma concentration-over-time profiles of a series of different steroids. LSD is a prototypic serotonergic hallucinogen that mainly acts as a potent serotonin $5-\mathrm{HT}_{1}$ and $5-\mathrm{HT}_{2}$ receptor agonist. It also binds to dopamine $D_{1-3}$ and adrenergic $\alpha_{1}$ receptors but does not inhibit monoamine transporters $(2,34)$. The LSD-induced increase in circulating glucocorticoids suggests a role for serotonin and $5-\mathrm{HT}_{1}$ and $5-\mathrm{HT}_{2}$ receptors in HPA axis stimulation. In the present study, LSD also increased plasma levels of prolactin (3), which is a marker of increased serotonergic activity (35, 
36). Similar to LSD in the present study, the hallucinogen psilocybin increased plasma levels of cortisol in healthy humans along with increases in prolactin and ACTH (37). Importantly, psilocybin (psilocin) activates 5-HT receptors similar to LSD, but does not exhibit relevant binding to $D_{1-3}$ and $\alpha_{1}$ receptors unlike LSD (34), further supporting the view, that HPA axis activation by serotonergic hallucinogens involves mainly 5-HT receptors. Consistently, it has been shown that $5-\mathrm{HT}_{2 \mathrm{~A} / \mathrm{C}}$ receptors stimulate $\mathrm{ACTH}$ and corticosterone release and activate CRF-expressing cells in the hypothalamic peraventricular nucleus $(38,39)$.

Stimulation of the HPA axis involves serotonin and norepinephrine systems (40). Similar to LSD, the serotonin and norepinephrine releaser MDMA increased the plasma concentrations of the glucocorticoids cortisol, corticosterone, and 11-dehydrocorticosterone (6). Unlike LSD and MDMA, methylphenidate, which activates dopamine and norepinephrine systems but not the serotonin system, did not significantly alter plasma steroid levels in humans $(6,41)$, further supporting a role for serotonin receptors in drug-induced HPA axis stimulation. Unexpectedly, the glucocorticoid response was more pronounced after LSD administration than after MDMA administration (6). This is consistent with the greater psychotropic response to LSD compared with MDMA (33); Supplemental Fig. S1A). In contrast, MDMA produced more stimulant-type effects, including greater increases in blood pressure and heart rate (33). The greater glucocorticoid response after LSD compared with MDMA indicates that the direct serotonergic stimulation of postsynaptic $5-\mathrm{HT}_{1}$ and $5-\mathrm{HT}_{2}$ receptors by LSD similarly or even more effectively stimulated the HPA axis compared with the release of both serotonin and norepinephrine by MDMA (42). The relatively similar time course of the glucocorticoid response and psychotropic effects of LSD, together with the greater glucocorticoid and psychotropic response to LSD compared with MDMA, raise the issue of whether the subjective effects of LSD contribute to or further enhance HPA axis stimulation by LSD. We observed a close relationship between LSDinduced subjective drug effects and changes in plasma corticosterone levels. Associations between amphetamine-induced increases in cortisol and subjective arousal and euphoria have 
been previously reported $(15,41)$. The covariance of the psychological and endocrine drug responses indicates that both are mediated by the same transmitter, likely norepinephrine in the case of amphetamine (41) and serotonin in the case of LSD. It is unlikely that glucocorticoids critically mediate the psychotropic drug response because the subjective effects of methamphetamine (43) and cocaine (44) are unaltered when the drug-induced cortisol response is pharmacologically augmented or blocked. On the other hand, the psychotropic effects of LSD might have contributed to the endocrine stress response. In fact, the subjective effects occurred faster than the cortisol response to LSD. However, only the subjective "good drug effects" and "stimulation" induced by LSD and not the "bad drug effects" or "fear" correlated with the steroid response over time. Thus, the endocrine changes in response to LSD seem be related to the positive and stimulant subjective LSD effects but not to anxiety.

Both cortisol and prolactin levels increase when the serotonin system is pharmacologically activated $(35,36,45)$. Interestingly, the prolactin response was greater after MDMA administration (33) than after LSD administration (3), whereas the glucocorticoid response was less, indicating differential effects of LSD and MDMA on markers of serotonergic activity and further supporting the view that the LSD-induced increase in glucocorticoids may have been enhanced by the more pronounced subjective effects of LSD.

A striking difference was found between the plasma concentration-effect curves of LSD in the present study and the plasma concentration-effect curves of MDMA in our previous study (33). Specifically, the plasma concentration-effect curve of MDMA showed pronounced clockwise hysteresis for the psychotropic effects of MDMA (33) and also for the cortisol and corticosterone responses (Supplemental Fig. S1A-C), suggesting acute tolerance to the effects of MDMA. In contrast, we observed no tolerance to the effects of LSD. This means that the effects of LSD on the HPA axis are longer-lasting than those of MDMA, although MDMA has a longer plasma half-life than $\operatorname{LSD}(31,33)$. The finding could be explained by the pharmacological mechanisms of MDMA and LSD. MDMA releases endogenous serotonin and 
norepinephrine from presynaptic terminals (42), whereas LSD directly interacts with postsynaptic 5-HT receptors (2). In fact, the MDMA-induced cortisol response was blocked after duloxetine pretreatment, which prevents MDMA from interacting with the serotonin and norepinephrine transporters (46). In the case of cocaine, cocaine-induced euphoria is also short-lasting and exhibits acute tolerance (12), similar to MDMA, whereas the cortisol concentration-time curve is concordant with the cocaine-plasma concentration time curve (12), similar to LSD.

Unlike LSD, MDMA also increased the mineralocorticoids 11-deoxycorticosterone and aldosterone. Mineralocorticoids promote sodium retention and increase extracellular fluid volume, thereby increasing blood pressure (25). The MDMA-induced increase in mineralocorticoids may thus contribute to the greater increase in blood pressure after MDMA administration (33) compared with LSD (3). The mechanisms that underlie the differential effects of MDMA and LSD on mineralocorticoid production remain unclear.

LSD increased DHEA. DHEA is a precursor of many other steroids and may itself modulate $\gamma$-aminobutyric acid-ergic and glutamatergic neurotransmission (47). DHEA has welldocumented anxiolytic and antidepressant effects (47-50). An interesting line of investigation would be to further evaluate the role of DHEA in the potential anxiolytic effects of LSD that are reported in terminally ill patients (4).

Many psychotropic drugs activate the HPA axis (5). Acute administration of serotonin transporter inhibitors $(35,51)$ but not dopamine transporter inhibitors $(6,41,52)$ increases plasma cortisol levels, indicating that serotonin rather than dopamine mediates HPA axis stimulation. Cocaine inhibits presynaptic serotonin, dopamine, and norepinephrine reuptake transporters and increases ACTH and cortisol in humans $(12,53)$. Amphetamine activates the norepinephrine and dopamine but not serotonin systems and increases cortisol $(15,41)$, although to a lesser extent than the serotonergic drugs LSD and MDMA. One speculation is that 
the stimulant-induced increase in cortisol may depend on dopamine-mediated HPA axis stimulation $(15,53)$. However, the stimulatory effects of amphetamines on ACTH secretion are mediated by adrenergic receptors (54) and not by dopamine (40). Additionally, methylphenidate activates the dopamine system and produces stimulation and euphoria that are similar to those produced by amphetamines $(33,55)$, but methylphenidate did not increase plasma cortisol levels $(6,41)$ or only to a small extent $(55)$. Furthermore, the MDMA-induced increase in circulating cortisol was reduced by pharmacologically blocking the MDMA-induced release of serotonin and norepinephrine $(42,46)$ but not when dopamine release was blocked $(52)$. The greater effects of amphetamine on cortisol release compared with methylphenidate are thus likely attributable to its greater noradrenergic vs. dopaminergic properties compared with methylphenidate $(41,56,57)$. Nonetheless, the present study showed that stimulation of the serotonin system by LSD increased cortisol levels similarly to MDMA, which has more amphetamine-type properties and stimulates both the serotonin and norepinephrine systems.

The present study has limitations. First, only a single dose and single administration of LSD were used. However, a relatively high dose of LSD was administered, which produced pronounced psychotropic effects and was within the range of doses used clinically (4) and recreationally $(1,2)$. Additionally, we present LSD exposure-effect relationships that can partially substitute for a multiple dose-level study. Second, only psychiatrically and somatically healthy subjects with limited previous experience with hallucinogenic drugs were included. LSD may differentially affect steroid profiles in chronic LSD or polydrug users. Third, we did not assess concentrations of corticotropin-releasing factor or ACTH to describe the drug's effects on other mediators within the HPA axis.

In conclusion, LSD induced significant effects on plasma glucocorticoids, consistent with HPA axis stimulation via serotonergic receptors. Plasma levels of cortisol and particularly corticosterone covaried in close relation to the plasma levels of LSD over time. The corticosterone response was also closely related to the subjective effects of LSD. The 
glucocorticoid response to LSD showed no acute pharmacological tolerance, in contrast to the response to MDMA.

\section{ACKNOWLEDGEMENTS}

We thank Florian Enzler for study management and M. Arends for manuscript editing. This study was supported by the Swiss Centre of Applied Human Toxicology (to AO) and the Swiss National Science Foundation (320030_1449493 to ML).

DECLARATION: The authors of the manuscript have not conflicts of interest to declare.

\section{Supplementary Data}

Supplementary data associated with this article can be found in the online version.

\section{REFERENCES}

1. Passie T, Halpern JH, Stichtenoth DO, Emrich HM, Hintzen A. The pharmacology of lysergic acid diethylamide: a review. CNS Neurosci Ther. 2008; 14(4): 295-314.

2. Nichols DE. Hallucinogens. Pharmacol Ther. 2004; 101(2): 131-81.

3. Schmid Y, Enzler F, Gasser P, Grouzmann E, Preller KH, Vollenweider FX, Brenneisen R, Muller F, Borgwardt S, Liechti ME. Acute effects of Iysergic acid diethylamide in healthy subjects. Biol Psychiatry. 2015; 78(8): 544-53.

4. Gasser P, Holstein D, Michel Y, Doblin R, Yazar-Klosinski B, Passie T, Brenneisen R. Safety and efficacy of lysergic acid diethylamide-assisted psychotherapy for anxiety associated with life-threatening diseases. J Nerv Ment Dis. 2014; 202(7): 513-20.

5. Armario A. Activation of the hypothalamic-pituitary-adrenal axis by addictive drugs: different pathways, common outcome. Trends Pharmacol Sci. 2010; 31(7): 318-25. 
6. Seibert J, Hysek CM, Penno CA, Schmid Y, Kratschmar DV, Liechti ME, Odermatt A. Acute effects of 3,4-methylenedioxymethamphetamine and methylphenidate on circulating steroid levels in healthy subjects. Neuroendocrinology. 2014; 10017-25.

7. Sackler AM, Weltman AS, Owens H. Effects of lysergic acid diethylamide on urinary 17ketosteroid and 17-OH corticosteroid levels of female rats. Nature. 1963; 1981119-20.

8. Mitra G, Poddar MK, Ghosh JJ. Interaction of delta9-tetrahydrocannabinol with reserpine, phenobarbital, and LSD-25 on plasma and adrenal corticosterone. Toxicol Appl Pharmacol. 1977; 42(3): 505-12.

9. Grossman L, Utterback E, Stewart A, Gaikwad S, Chung KM, Suciu C, Wong K, Elegante M, Elkhayat S, Tan J, Gilder T, Wu N, Dileo J, Cachat J, Kalueff AV. Characterization of behavioral and endocrine effects of LSD on zebrafish. Behav Brain Res. 2010; 214(2): 277-84.

10. Hoagland $\mathrm{H}$, Rinkel M, Hyde RW. Adrenocortical function and urinary phosphate excretion; comparison in schizophrenia and in lysergic acid diethylamide-induced psychotic episodes in normal persons. AMA Arch Neurol Psychiatry. 1955; 73(1): 100-9.

11. Hollister LE. Steroids and moods: correlations in schizophrenics and subjects treated with lysergic acid diethylamide (LSD), mescaline, tetrahydrocannabinol, and synhexyl. $J$ Clin Pharmacol J New Drugs. 1969; 9(1): 24-9.

12. Mendelson JH, Mello NK, Sholar MB, Siegel AJ, Mutschler N, Halpern J. Temporal concordance of cocaine effects on mood states and neuroendocrine hormones. Psychoneuroendocrinology. 2002; 27(1-2): 71-82.

13. Evans SM. The role of estradiol and progesterone in modulating the subjective effects of stimulants in humans. Exp Clin Psychopharmacol. 2007; 15(5): 418-26.

14. Harris DS, Baggott M, Mendelson JH, Mendelson JE, Jones RT. Subjective and hormonal effects of 3,4-methylenedioxymethamphetamine (MDMA) in humans. Psychopharmacology (Berl). 2002; 162(4): 396-405. 
15. Oswald LM, Wong DF, McCaul M, Zhou Y, Kuwabara H, Choi L, Brasic J, Wand GS. Relationships among ventral striatal dopamine release, cortisol secretion, and subjective responses to amphetamine. Neuropsychopharmacology. 2005; 30(4): 821-32.

16. Hamidovic A, Childs E, Conrad M, King A, de Wit H. Stress-induced changes in mood and cortisol release predict mood effects of amphetamine. Drug Alcohol Depend. 2010; 109(1-3): 175-80.

17. Eisenegger C, Haushofer J, Fehr E. The role of testosterone in social interaction. Trends Cogn Sci. 2011; 15(6): 263-71.

18. Hysek CM, Schmid Y, Simmler LD, Domes G, Heinrichs M, Eisenegger C, Preller KH, Quednow BB, Liechti ME. MDMA enhances emotional empathy and prosocial behavior. Soc Cogn Affect Neurosci. 2014; 91645-52.

19. Mello NK, Knudson IM, Kelly M, Fivel PA, Mendelson JH. Effects of progesterone and testosterone on cocaine self-administration and cocaine discrimination by female rhesus monkeys. Neuropsychopharmacology. 2011; 36(11): 2187-99.

20. Sofuoglu M, Babb DA, Hatsukami DK. Effects of progesterone treatment on smoked cocaine response in women. Pharmacol Biochem Behav. 2002; 72(1-2): 431-5.

21. Yonkers KA, Forray A, Nich C, Carroll KM, Hine C, Merry BC, Shaw H, Shaw J, Sofuoglu M. Progesterone reduces cocaine use in postpartum women with a cocaine use disorder: a randomized,double-blind study. Lancet Psychiatry. 2014; 1(5): 360-7.

22. Bosch OG, Eisenegger C, Gertsch J, von Rotz R, Dornbierer D, Gachet MS, Heinrichs M, Wetter TC, Seifritz E, Quednow BB. Gamma-hydroxybutyrate enhances mood and prosocial behavior without affecting plasma oxytocin and testosterone. Psychoneuroendocrinology. 2015; 621-10.

23. Lu NZ, Wardell SE, Burnstein KL, Defranco D, Fuller PJ, Giguere V, Hochberg RB, McKay L, Renoir JM, Weigel NL, Wilson EM, McDonnell DP, Cidlowski JA. International Union of Pharmacology. LXV. The pharmacology and classification of the nuclear 
receptor superfamily: glucocorticoid, mineralocorticoid, progesterone, and androgen receptors. Pharmacol Rev. 2006; 58(4): 782-97.

24. Karssen AM, Meijer OC, van der Sandt IC, Lucassen PJ, de Lange EC, de Boer AG, de Kloet ER. Multidrug resistance P-glycoprotein hampers the access of cortisol but not of corticosterone to mouse and human brain. Endocrinology. 2001; 142(6): 2686-94.

25. Connell JM, Fraser R, Davies E. Disorders of mineralocorticoid synthesis. Best Pract Res Clin Endocrinol Metab. 2001; 15(1): 43-60.

26. Odermatt A, Kratschmar DV. Tissue-specific modulation of mineralocorticoid receptor function by 11 beta-hydroxysteroid dehydrogenases: an overview. Mol Cell Endocrinol. 2012; 350(2): 168-86.

27. Azizi M, Amar L, Menard J. Aldosterone synthase inhibition in humans. Nephrol Dial Transplant. 2013; 28(1): 36-43.

28. Oddie CJ, Coghlan JP, Scoggins BA. Plasma desoxycorticosterone levels in man with simultaneous measurement of aldosterone, corticosterone, cortisol and 11-deoxycortisol. J Clin Endocrinol Metab. 1972; 34(6): 1039-54.

29. Johnson M, Richards W, Griffiths R. Human hallucinogen research: guidelines for safety. J Psychopharmacol. 2008; 22(6): 603-20.

30. Dolder PC, Liechti ME, Rentsch KM. Development and validation of a rapid turboflow LC-MS/MS method for the quantification of LSD and 2-0xo-3-hydroxy LSD in serum and urine samples of emergency toxicological cases. Anal Bioanal Chem. 2015; 4071577-84.

31. Dolder PC, Schmid Y, Haschke M, Rentsch KM, Liechti ME. Pharmacokinetics and concentration-effect relationship of oral LSD in humans. Int $J$ Neuropsychopharmacol. 2015; doi: 10.1093/ijnp/pyv072.

32. Hysek CM, Simmler LD, Ineichen M, Grouzmann E, Hoener MC, Brenneisen R, Huwyler J, Liechti ME. The norepinephrine transporter inhibitor reboxetine reduces stimulant effects of MDMA ("ecstasy") in humans. Clin Pharmacol Ther. 2011; 90(2): 246-55. 
33. Hysek CM, Simmler LD, Schillinger N, Meyer N, Schmid Y, Donzelli M, Grouzmann E, Liechti ME. Pharmacokinetic and pharmacodynamic effects of methylphenidate and MDMA administered alone and in combination. Int J Neuropsychopharmacol. 2014; $17371-81$

34. Rickli A, Luethi D, Reinisch J, Buchy D, Hoener MC, Liechti ME. Receptor interaction profiles of novel N-2-methoxybenzyl (NBOMe) derivatives of 2,5-dimethoxy-substituted phenethylamines (2C drugs). Neuropharmacology. 2015; 99546-53.

35. Seifritz E, Baumann P, Muller MJ, Annen O, Amey M, Hemmeter U, Hatzinger M, Chardon F, Holsboer-Trachsler E. Neuroendocrine effects of a 20-mg citalopram infusion in healthy males. a placebo-controlled evaluation of citalopram as 5-HT function probe. Neuropsychopharmacology. 1996; 14(4): 253-63.

36. Murphy DL, Mueller EA, Garrick NA, Aulakh CS. Use of serotonergic agents in the clinical assessment of central serotonin function. J Clin Psychiatry. 1986; 47 Suppl9-15.

37. Hasler F, Grimberg U, Benz MA, Huber T, Vollenweider FX. Acute psychological and physiological effects of psilocybin in healthy humans: a double-blind, placebo-controlled dose-effect study. Psychopharmacology. 2004; 172(2): 145-56.

38. Van de Kar LD, Javed A, Zhang Y, Serres F, Raap DK, Gray TS. 5-HT2A receptors stimulate $\mathrm{ACTH}$, corticosterone, oxytocin, renin, and prolactin release and activate hypothalamic CRF and oxytocin-expressing cells. J Neurosci. 2001; 21(10): 3572-9.

39. Fuller RW. Serotonergic stimulation of pituitary-adrenocortical function in rats. Neuroendocrinology. 1981; 32(2): 118-27.

40. Frohman LA, Stachura ME. Neuropharmacologic control of neuroendocrine function in man. Metabolism. 1975; 24(2): 211-34.

41. Brown WA, Corriveau DP, Ebert MH. Acute psychologic and neuroendocrine effects of dextroamphetamine and methylphenidate. Psychopharmacology (Berl). 1978; 58(2): 189-95. 
42. Hysek CM, Simmler LD, Nicola V, Vischer N, Donzelli M, Krähenbühl S, Grouzmann E, Hoener MC, Liechti ME. Duloxetine inhibits effects of MDMA ("ecstasy") in vitro and in humans in a randomized placebo-controlled laboratory study. PLoS One. 2012; $7 e 36476$.

43. Harris DS, Reus VI, Wolkowitz OM, Mendelson JE, Jones RT. Altering cortisol level does not change the pleasurable effects of methamphetamine in humans. Neuropsychopharmacology. 2003; 28(9): 1677-84.

44. Ward AS, Collins ED, Haney M, Foltin RW, Fischman MW. Blockade of cocaine-induced increases in adrenocorticotrophic hormone and cortisol does not attenuate the subjective effects of smoked cocaine in humans. Behav Pharmacol. 1999; 10(5): 523-9.

45. Lennartsson AK, Jonsdottir IH. Prolactin in response to acute psychosocial stress in healthy men and women. Psychoneuroendocrinology. 2011; 36(10): 1530-9.

46. Hysek CM, Domes G, Liechti ME. MDMA enhances "mind reading" of positive emotions and impairs "mind reading" of negative emotions. Psychopharmacology (Berl). 2012; 222293-302.

47. Kroboth PD, Salek FS, Pittenger AL, Fabian TJ, Frye RF. DHEA and DHEA-S: a review. J Clin Pharmacol. 1999; 39(4): 327-48.

48. Wolkowitz OM, Reus VI, Keebler A, Nelson N, Friedland M, Brizendine L, Roberts E. Double-blind treatment of major depression with dehydroepiandrosterone. Am J Psychiatry. 1999; 156(4): 646-9.

49. Schmidt PJ, Daly RC, Bloch M, Smith MJ, Danaceau MA, St Clair LS, Murphy JH, Haq N, Rubinow DR. Dehydroepiandrosterone monotherapy in midlife-onset major and minor depression. Arch Gen Psychiatry. 2005; 62(2): 154-62.

50. Sripada RK, Marx CE, King AP, Rajaram N, Garfinkel SN, Abelson JL, Liberzon I. DHEA enhances emotion regulation neurocircuits and modulates memory for emotional stimuli. Neuropsychopharmacology. 2013; 38(9): 1798-807. 
51. Nadeem HS, Attenburrow MJ, Cowen PJ. Comparison of the effects of citalopram and escitalopram on 5-HT-mediated neuroendocrine responses. Neuropsychopharmacology. 2004; 29(9): 1699-703.

52. Schmid Y, Rickli A, Schaffner A, Duthaler U, Grouzmann E, Hysek CM, Liechti ME. Interactions between bupropion and 3,4-methylenedioxymethamphetamine in healthy subjects. J Pharmacol Exp Ther. 2015; 353(1): 102-11.

53. Mendelson JH, Teoh SK, Mello NK, Ellingboe J, Rhoades E. Acute effects of cocaine on plasma adrenocorticotropic hormone, luteinizing hormone and prolactin levels in cocaine-dependent men. J Pharmacol Exp Ther. 1992; 263(2): 505-9.

54. Rees L, Butler PW, Gosling C, Besser GM. Adrenergic blockade and the corticosteroid and growth hormone responses to methylamphetamine. Nature. 1970; 228(5271): 565-6.

55. Schmid Y, Hysek CM, Simmler LD, Crockett MJ, Quednow BB, Liechti ME. Differential effects of MDMA and methylphenidate on social cognition. J Psychopharmacol. 2014; 28847-56.

56. Simmler L, Buser T, Donzelli M, Schramm Y, Dieu LH, Huwyler J, Chaboz S, Hoener M, Liechti ME. Pharmacological characterization of designer cathinones in vitro. $\mathrm{Br} J$ Pharmacol. 2013; 168(2): 458-70.

57. Simmler LD, Rickli A, Schramm Y, Hoener MC, Liechti ME. Pharmacological profiles of aminoindanes, piperazines, and pipradrol derivatives. Biochem Pharmacol. 2014; 88(2): 237-44. 
Table 1. Plasma steroid concentrations following LSD or placebo adminstration.

\begin{tabular}{|c|c|c|c|c|c|c|c|c|}
\hline & \multicolumn{4}{|c|}{$\mathrm{C}_{\max }$} & \multicolumn{4}{|c|}{$\mathrm{AUC}_{10}$} \\
\hline & Placebo & LSD & ${ }^{\mathrm{a}} \mathrm{F}_{1,15}$ & $P$ value & Placebo & LSD & ${ }^{\mathrm{a}} \mathrm{F}_{1,15}$ & $P$ value \\
\hline \multicolumn{9}{|l|}{ Glucocorticoids } \\
\hline Cortisol, nM & $691 \pm 77$ & $1060 \pm 40$ & 19.78 & $<0.001$ & $3545 \pm 247$ & $6160 \pm 256$ & 45.85 & $<0.001$ \\
\hline 11-Dehydrocorticosterone, $\mathrm{nM}$ & $4.43 \pm 0.7$ & $8.70 \pm 0.7$ & 13.97 & $<0.01$ & $25.7 \pm 3.4$ & $39.8 \pm 4.4$ & 4.16 & NS \\
\hline Cortisol + Cortisone & $737 \pm 81$ & $1119 \pm 41$ & 18.96 & $<0.001$ & $3886 \pm 260$ & $6666 \pm 267$ & 45.86 & $<0.001$ \\
\hline Cortisol/Cortisone ratio & $13.9 \pm 1.1$ & $20.1 \pm 1.3$ & 32.76 & $<0.001$ & $99.4 \pm 7.4$ & $120 \pm 7.7$ & 10.89 & $<0.01$ \\
\hline 11-Deoxycortisol (precursor of cortisol), nM & $1.67 \pm 0.3$ & $2.53 \pm 0.5$ & 2.09 & NS & $13.0 \pm 2.0$ & $13.0 \pm 3.1$ & 0.00 & NS \\
\hline Corticosterone + 11-Dehydrocorticosterone & $11.7 \pm 1.6$ & $46.4 \pm 4.2$ & 46.00 & $<0.001$ & $53.6 \pm 5.2$ & $141 \pm 13.5$ & 27.67 & $<0.001$ \\
\hline 11-Deoxycorticosterone, $\mathrm{nM}$ & $0.93 \pm 0.16$ & $1.16 \pm 0.17$ & 0.50 & NS & $7.03 \pm 1.5$ & $9.94 \pm 1.7$ & 0.99 & NS \\
\hline \multicolumn{9}{|l|}{ Androgens } \\
\hline DHEA, nM & $11.1 \pm 1.3$ & $19.1 \pm 2.3$ & 12.12 & $<0.01$ & $71.9 \pm 6.8$ & $106 \pm 12.1$ & 10.33 & $<0.01$ \\
\hline DHEAS, nM & $1761 \pm 234$ & $2070 \pm 318$ & 1.03 & NS & $11551 \pm 1751$ & $15224 \pm 2509$ & 1.94 & NS \\
\hline Androsterone, $\mathrm{nM}$ & $4.03 \pm 0.3$ & $3.59 \pm 0.2$ & 1.53 & NS & $26.3 \pm 1.1$ & $27.0 \pm 0.9$ & 0.23 & NS \\
\hline Androstendione, $\mathrm{nM}$ & $3.68 \pm 0.5$ & $4.37 \pm 0.5$ & 2.03 & NS & $22.5 \pm 2.2$ & $28.8 \pm 3.0$ & 8.59 & $<0.01$ \\
\hline Testosterone, nM & $10.2 \pm 2.3$ & $9.15 \pm 2.1$ & 0.80 & NS & $71.8 \pm 17.1$ & $71.3 \pm 15.8$ & 0.54 & NS \\
\hline Testosterone in women, $\mathrm{nM}$ & $2.07 \pm 0.4$ & $1.58 \pm 0.3$ & 1.30 & NS & $11.2 \pm 1.7$ & $11.9 \pm 3.4$ & 0.10 & NS \\
\hline Testosterone in men, $\mathrm{nM}$ & $18.3 \pm 1.9$ & $16.7 \pm 1.6$ & 0.44 & NS & $132.4 \pm 14.1$ & $123.3 \pm 9.9$ & 0.65 & NS \\
\hline
\end{tabular}

Values are mean \pm SEM in 16 subjects. DHEA, dehydroepiandrosterone; DHEAS, dehydroepiandrosterone sulfate; $\mathrm{C}_{\text {max }}$, peak plasma concentration; $\mathrm{AUC}_{10}$, area under the concentration-time curve up to $10 \mathrm{~h}$. NS, not significant. ${ }^{\mathrm{a}} \mathrm{F}_{1,7}$ if only men or women. 


\section{FIGURES and FIGURE LEGENDS}




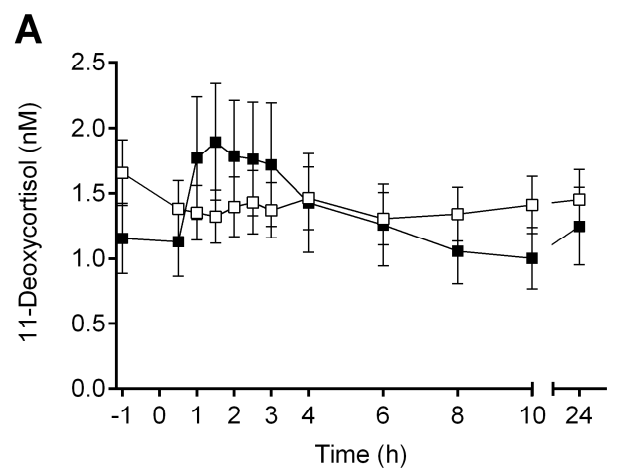

B

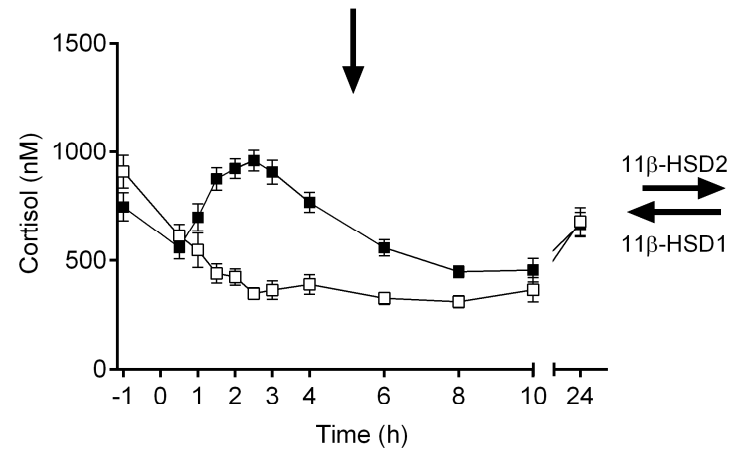

D

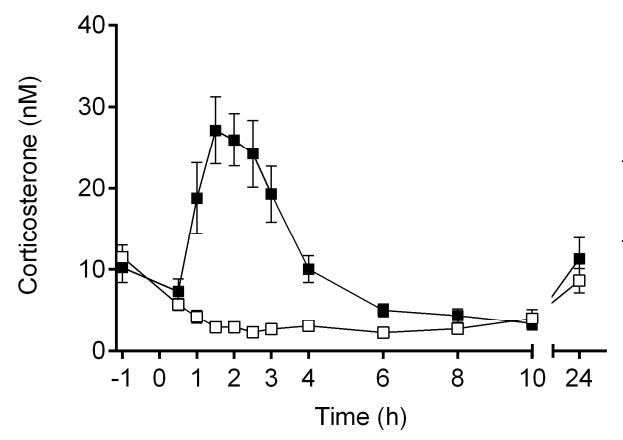

F

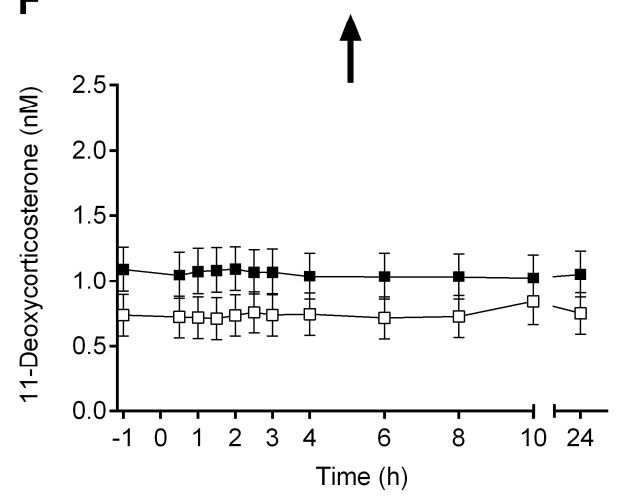

11ß-HSD2

11 $\beta$-HSD1
C

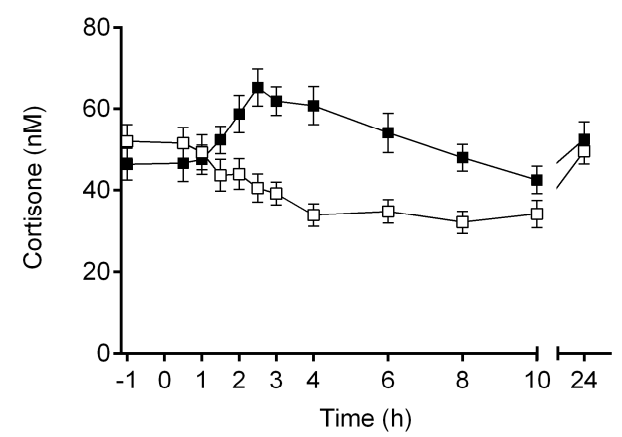

E

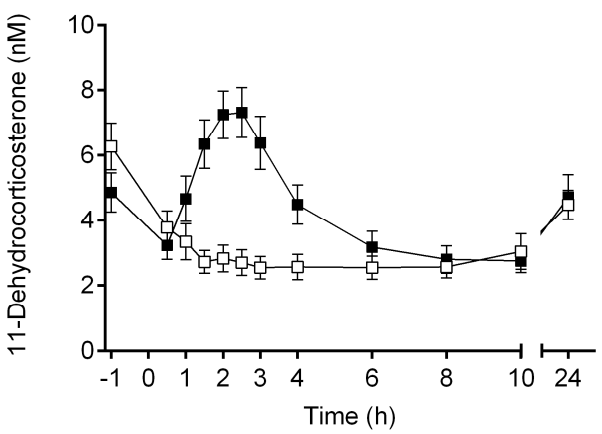

G

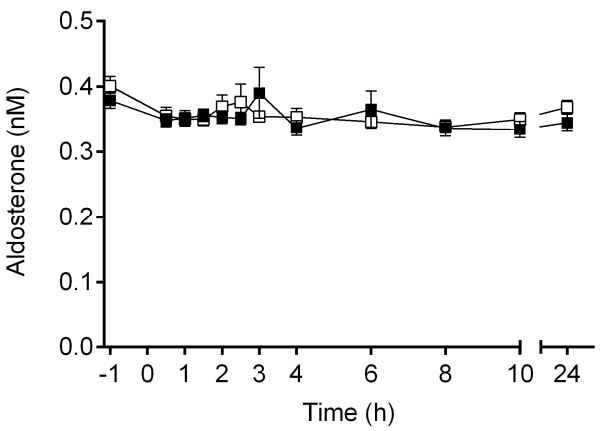


Figure 1. Plasma concentration-time profiles of glucocorticoids and mineralocorticoids following LSD or placebo administration. The values, obtained from 16 subjects, are expressed as mean \pm SEM. LSD or placebo was administered at $\mathrm{t}=0 \mathrm{~h}$. LSD significantly increased the plasma concentrations of the glucocorticoids cortisol (B), cortisone (C), corticosterone (D), and 11dehydrocorticosterone $(E)$ compared with placebo. LSD did not alter plasma concentrations of the cortisol precursor 11-deoxycortisol $(A)$ or the mineralocorticoids 11-deoxycorticosterone $(F)$ and aldosterone (G). 11ß-HSD, 11ß-hydroxysteroid dehydrogenase; CYP, cytochrome P450. 


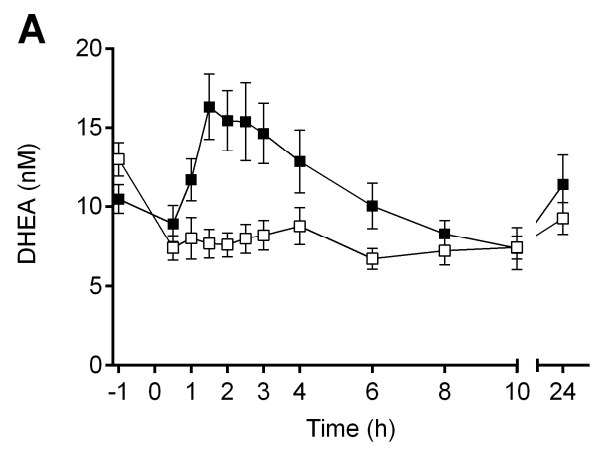

C

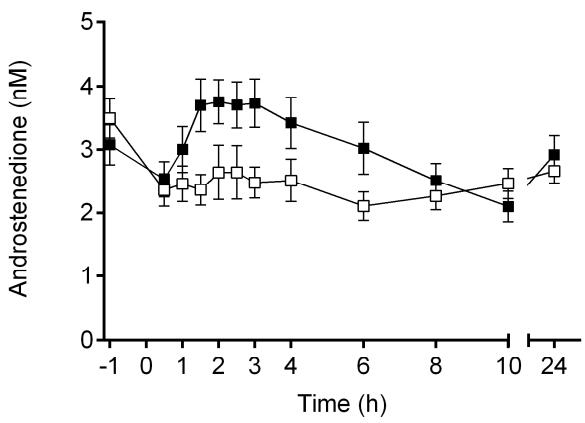

E

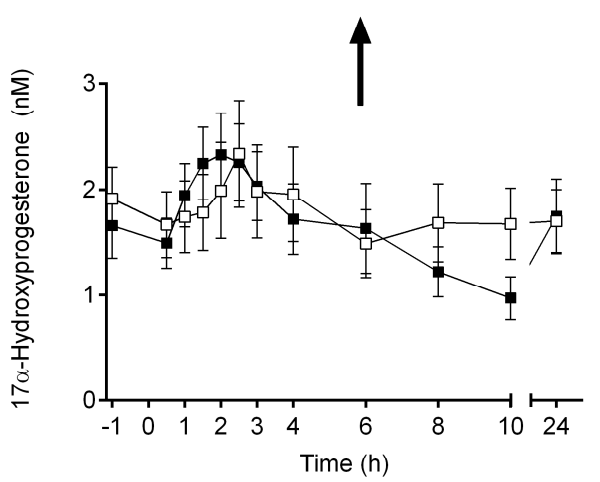

G

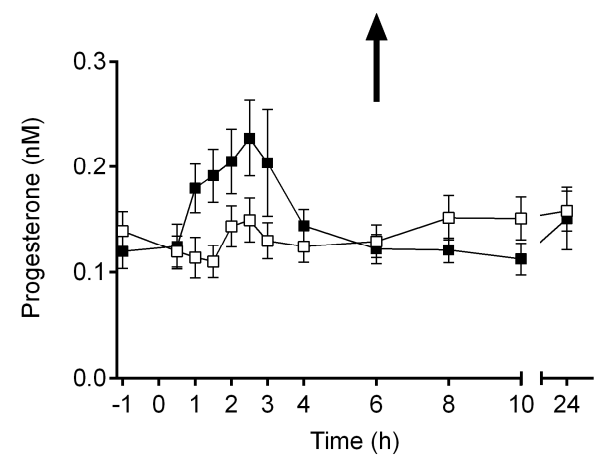

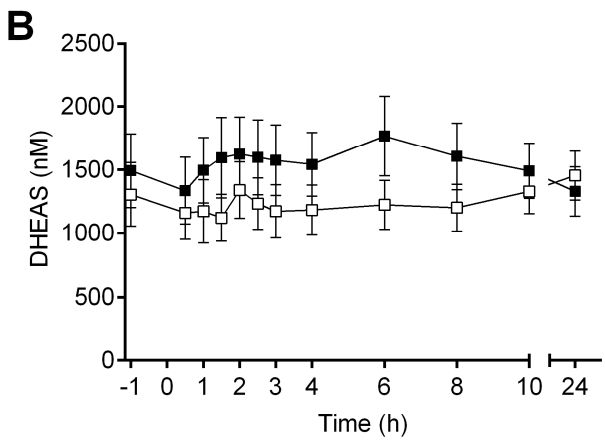

D

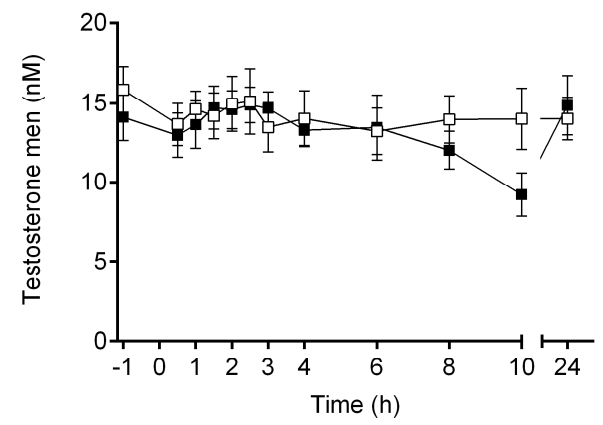

F

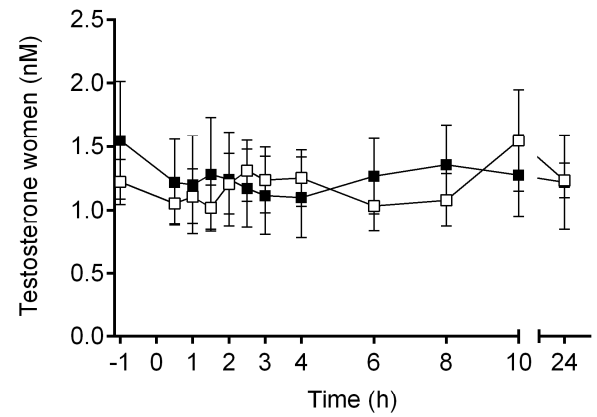

- - Placebo

- LSD 
Figure 2. Plasma concentration-time profiles of androgens and progestogens following LSD or placebo administration. The values, obtained from 16 subjects (eight per sex for testosterone), are expressed as mean \pm SEM. LSD or placebo was administered at $t=0 \mathrm{~h}$. LSD significantly increased plasma concentrations of dehydroepiandrosterone (DHEA) compared with placebo (A). LSD also increased the area under the concentration-time curve but not the maximal concentration of androstenedione compared with placebo (C). In contrast, LSD did not alter plasma concentrations of dehydroepiandrosterone sulfate (DHEAS) (B) or testosterone (D, F). Similarly, LSD did not change plasma levels of the progestogens progesterone $(G)$ and $17 a-$ hydroxyprogesterone (E). 17ß-HSD, 17ß-hydroxysteroid dehydrogenase; CYP, cytochrome P450. 
A

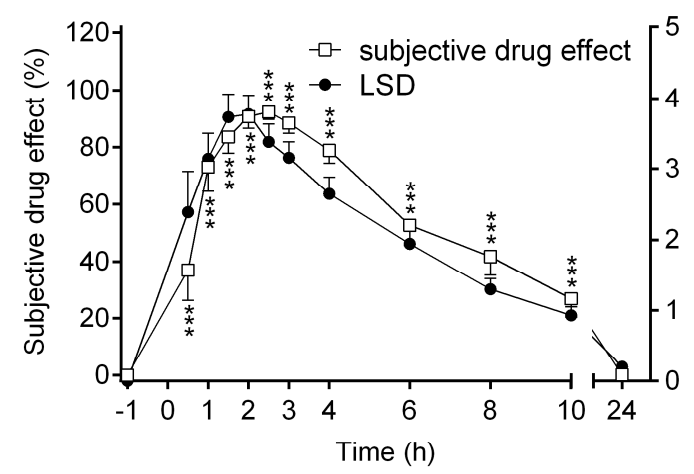

C

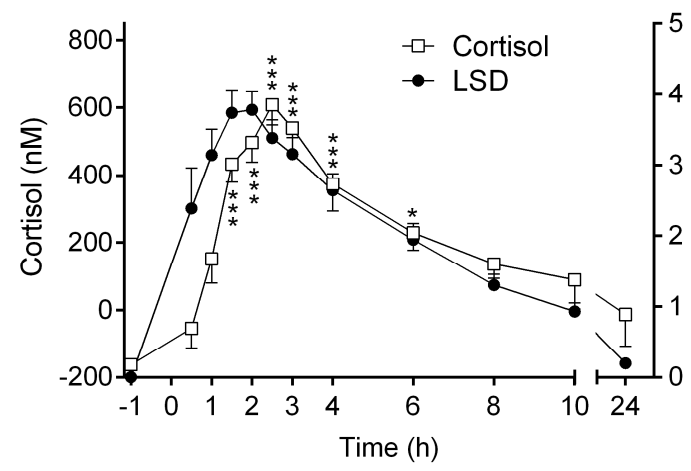

E

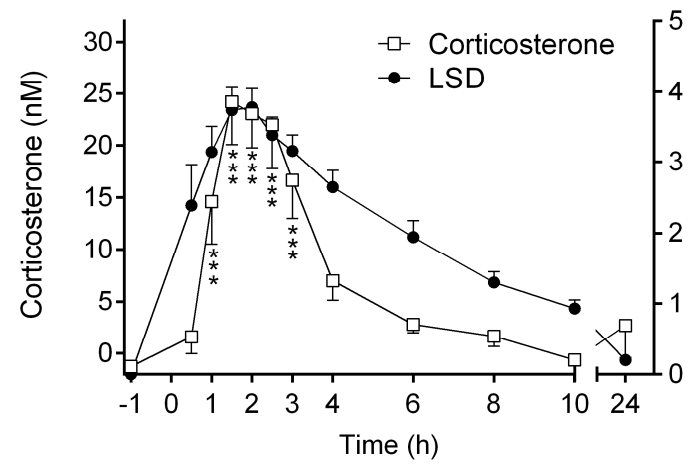

G

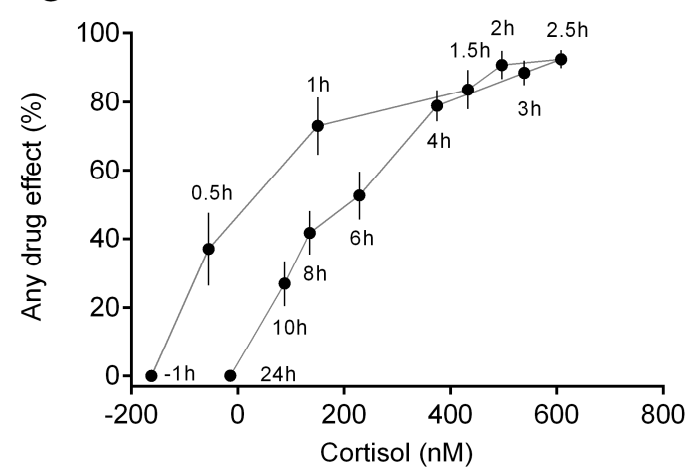

B

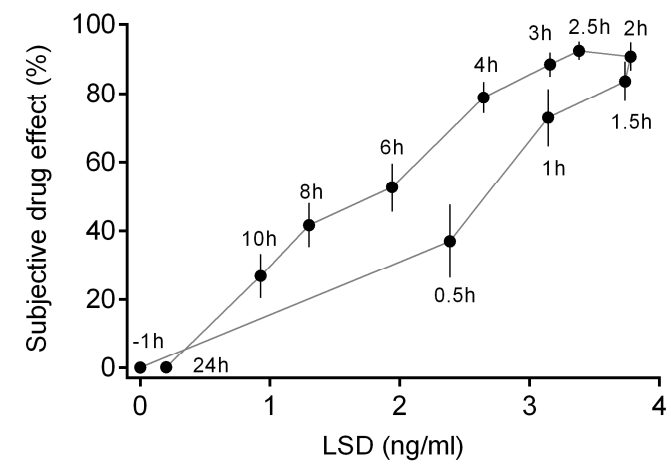

D

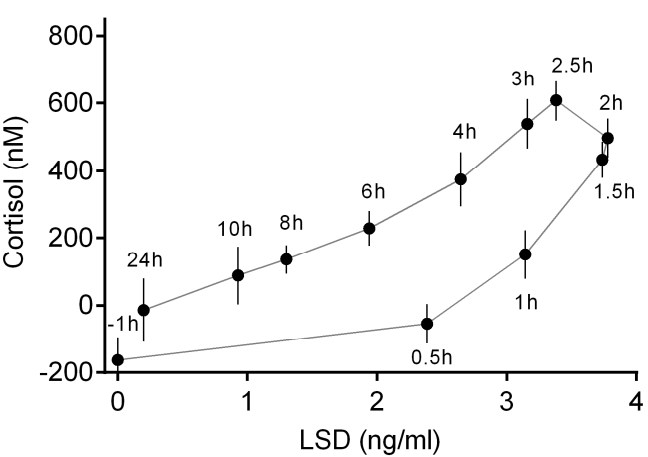

F

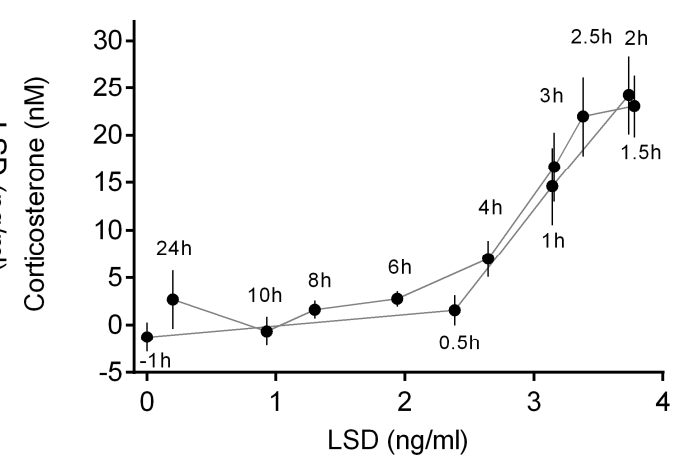

H

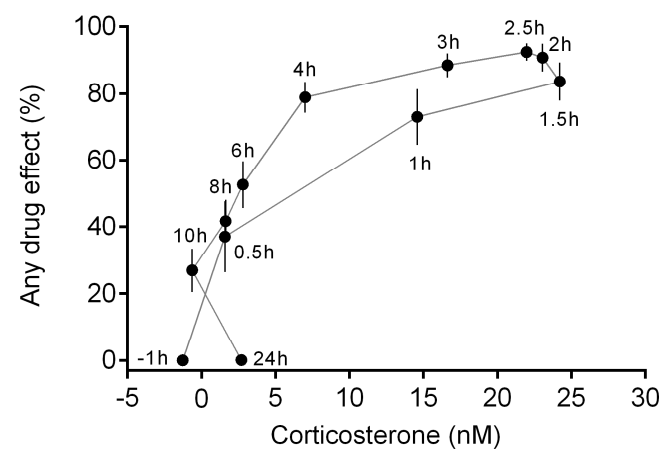


Figure 3. LSD exposure-response relationships. LSD responses are shown as LSD effect (any subjective drug effect, cortisol or corticosterone concentration) minus the individual timematched effect of placebo. Subjective responses to LSD (A) and LSD-induced changes in cortisol (C) and corticosterone (E) over time are presented with the corresponding LSD concentrations over time (mean \pm SEM) in 16 subjects. LSD or placebo was administered at $t=$ 0 h. Subjective responses to LSD (B) and LSD-induced changes in cortisol (D) and corticosterone $(F)$ concentrations (mean \pm SEM) are plotted as a function of mean LSD plasma concentrations (hysteresis curves). The time of sampling is noted next to each point (in hours after LSD administration). The maximum concentration of LSD was reached $1.7 \pm 1 \mathrm{~h}$ after LSD administration (A, B). The peak psychotropic effect was reached at $2.4 \pm 0.8 \mathrm{~h}$, with significant alterations in mental state from $0.5 \mathrm{~h}$ to $>10 \mathrm{~h}$ after LSD administration (A, B) (drug $\times$ time interaction in the two-way ANOVA: $\left.F_{11,165}=41.39 ; P<0.001\right)$. Maximum concentrations of cortisol $(C, D)$ and corticosterone $(E, F)$ were reached at $2.5 \pm 0.8 \mathrm{~h}$ and $1.9 \pm 0.5 \mathrm{~h}$ (mean \pm $\mathrm{SD})$, with significant elevations from 1.5 to $6 \mathrm{~h}$ and from 1 to $3 \mathrm{~h}$ after LSD administration, respectively $\left(\mathrm{F}_{11,165}=17.71 ; \mathrm{P}<0.01\right.$ and $\mathrm{F}_{11,165}=13.35, \mathrm{P}<0.001$, respectively $)$. Counterclockwise hysteresis was observed for any drug effects (B) and cortisol (D), consistent with an initial delay between plasma concentration and effect that was attributable to drug absorption. Beyond $2 \mathrm{~h}$ after LSD administration, the psychotropic effects $(\mathrm{A})$ and changes in plasma cortisol levels $(C)$ decreased slowly, in parallel with the plasma levels of LSD, exhibiting a close concentration-effect relationship up to $24 \mathrm{~h}(\mathrm{~B}, \mathrm{D})$. LSD significantly increased plasma levels of cortisol 1.5-6 $\mathrm{h}$ after LSD administration (C). In contrast, plasma levels of corticosterone increased more rapidly but fell more quickly back to baseline levels, resulting in significant differences in plasma levels 1-3 $\mathrm{h}$ after LSD administration and compared with placebo (E). There was no evidence of acute pharmacological tolerance (clockwise hysteresis) 
for any of the effects of LSD. After drug administration, subjective drug effects increased together with plasma levels of corticosterone but more rapidly than plasma levels of cortisol ( $G$, H). ${ }^{*} P<0.05$ and ${ }^{* * *} P<0.001$, compared with the time-matched placebo concentration (Tukey tests based on significant drug $\times$ time interactions in the two-way ANOVAs. 


\section{Supplementary data}

Acute effects of LSD on circulating steroid levels in healthy subjects

Petra Strajhar, ${ }^{\mathrm{a}, 1}$ Yasmin Schmid, ${ }^{\mathrm{b}, 1}$ Evangelia Liakoni, ${ }^{\mathrm{b}}$ Patrick C. Dolder, ${ }^{\mathrm{b}, \mathrm{c}}$ Katharina M. Rentsch, ${ }^{\mathrm{c}}$ Denise V. Kratschmar, ${ }^{\mathrm{a}}$ Alex Odermatt, ${ }^{\mathrm{a}, 2}$ and Matthias E. Liechti ${ }^{\mathrm{b}, 2}$

\section{Supplemental methods:}

\section{Quantification of steroid hormones in human plasma samples}

\subsection{Chemicals and reagents}

UPLC-grade purity methanol, acetonitrile and formic acid were purchased from Sigma-Aldrich (St. Louis, MO) or Biosolve (Dieuze, France). Distilled water was deionized using a MilliQ water purification system (Millipore, USA). Aldosterone, 11-deoxycorticosterone, corticosterone, dehydroepiandrosterone-3-sulfate, androstenedione, testosterone and $\left[2,2,4,6,6,21,21-{ }^{2} \mathrm{H}_{7}\right]-$ aldosterone (98\% isotopic purity) were purchased from Sigma-Aldrich (St. Louis, MO). 11Dehydrocorticosterone, dehydroepiandrosterone (DHEA), 5a-dihydrotestosterone, androsterone, progesterone, 17a-hydroxyprogesterone, 11-deoxycortisol, cortisol, cortisone, $\left[16,16-{ }^{2} \mathrm{H}_{2}\right]$-androsterone (98\% isotopic purity) and $\left[16,16,17-{ }^{2} \mathrm{H}_{3}\right]-5 \alpha$-dihydrotestosterone (98\% isotopic purity) were purchased from Steraloids (Newport, RI). [1,2- $\left.{ }^{2} \mathrm{H}_{2}\right]$-Testosterone (98\% isotopic purity), $\left[2,2,4,6,6,16,16-{ }^{2} \mathrm{H}_{7}\right]-4$-androsten-3,17-Dione $(98 \%$ isotopic purity) and $\left[2,2,4,6,6,17 \alpha, 21,21-{ }^{2} \mathrm{H}_{8}\right]$-corticosterone (98\% isotopic purity) were purchased from $\mathrm{C} / \mathrm{D} / \mathrm{N}$ Isotopes Inc. (Pointe-Claire, Canada). All other chemicals were purchased from Sigma-Aldrich (St. Louis, MO) and of the highest grade available. 


\subsection{Instrumentation and analytical conditions}

Analytical instruments: All analytes were measured simultaneously by ultra-pressure liquid chromatography-tandem mass spectrometry (UPLC-MS/MS) using a Agilent 1290 UPLC instrument equipped with a binary solvent delivery system, an auto sampler (at $4{ }^{\circ} \mathrm{C}$ ), and a column oven, coupled to an Agilent 6490 triple quadrupole mass spectrometer equipped with a jet stream electrospray ionization interface (AJS-ESI) (Agilent Technologies, Basel, Switzerland).

Liquid chromatography: The chromatographic separation of the analytes was achieved using a Waters ACQUITY UPLC BEH C18, $1.7 \mu \mathrm{m}, 2.1 \times 150 \mathrm{~mm}$, column (Waters, Wexford, Ireland). The column temperature was maintained at $65{ }^{\circ} \mathrm{C}$. Steroids were separated using a mobile phase consisting of water-acetonitrile-formic acid (A) (95/5/0.1; v/v/v) and (B) $(5 / 95 / 0.1 ; \mathrm{v} / \mathrm{v} / \mathrm{v})$. The injection volume was $5 \mu \mathrm{L}$ per sample. Methanol in water $(50 / 50 \mathrm{v} / \mathrm{v})$ was used as needle and needle-seat flushing solvent for $10 \mathrm{~s}$ after sample aspiration. Samples were stored until analysis in the auto sampler (maintained at $4^{\circ} \mathrm{C}$ ). Method A: Aldosterone, corticosterone, 11dehydrocorticosterone, cortisol, cortisone, DHEA, DHEA-3-sulfate, progesterone, 17ahydroxyprogesterone, 11-deoxycortisol, 11-deoxycorticosterone, aldosterone-d7, and corticosterone-d8 were eluted by the gradient $25-70 \%$ of mobile phase B during $0-10$ min, and $100 \%$ of mobile phase $B$ at 10.1 min onwards at a constant flow rate of $0.63 \mathrm{~mL} / \mathrm{min}$. The run was stopped after $12.0 \mathrm{~min}$, followed by re-equilibration of the column for $2 \mathrm{~min}$. Method $B$ : Androsterone, testosterone, androstenedione, 5a-dihydrotestosterone, androsterone-d2, testosterone-d2, androstenedione-d7, and 5a-dihydrotestosterone-d3 were eluted by the gradient of $25-59 \%$ of mobile phase B during $0-20$ min at a gradient flow rate from 0.65 $\mathrm{mL} / \mathrm{min}$ to $0.36 \mathrm{~mL} / \mathrm{min}$, and $100 \%$ of mobile phase $\mathrm{B}$ at 22 min onwards at a constant flow rate of $0.65 \mathrm{~mL} / \mathrm{min}$. The run was stopped at $24 \mathrm{~min}$, followed by re-equilibration of the column for 1 $\min$. 
Mass spectrometry: The AJS-ESI source was operated with nitrogen as drying and collision gas in the positive ion mode for all analytes, except for aldosterone and aldosterone-d7, which were analyzed using negative ionization. The ion source conditions were identified and optimized for all individual analytes using the source optimization software module (Agilent Technologies, California, USA, B.07.01) (Supplemental Table S1). Analytes were monitored by multiple reaction-monitoring (MRM) and characteristic precursor ions and corresponding transitions for quantifier- and qualifier-ions were automated defined by the use of the compound optimizer software module included within the Mass Hunter Workstation software (Agilent Technologies, California, USA) (Supplemental Table S2).

Data analysis: Data acquisition and subsequent data analysis was performed using Mass Hunter Workstation Acquisition software Version 07.01 SP1 and MassHunter Workstation Software Quantitative Analysis Version B.07.00 /Build 7.0457.0, respectively (Agilent Technologies, California, USA).

Sample extraction: Sample extraction was performed using a vacuum manifold (Agilent Technologies, California, USA) equipped with Oasis HBL SPE cartridges (Waters, Massachusetts; USA, Lot No. 116B32307A). Samples were evaporated to dryness using a Genevac EZ-2 plus centrifugal vacuum evaporator (Genevac, Suffolk, UK).

Standard solutions: Stock solutions of analytes and deuterium internal standards (I.S.) were prepared by weighing pure compounds on an analytical balance (Mettler-Toledo, Switzerland) and dissolving in methanol to obtain a concentration of $10 \mathrm{mM}$ for analytes and I.S. The standard solutions of analytes and I.S. were freshly prepared in methanol by further diluting the corresponding stock solution to obtain a concentration of $100 \mu \mathrm{M}$. All stock solutions of standards and I.S. were stored at $-20 \stackrel{\circ}{ } \mathrm{C}$.

Sample preparation: For solid phase extraction each sample, calibrator or quality control (QC) $(700 \mu \mathrm{L})$ was mixed with protein precipitation solution $(100 \mu \mathrm{L}$, zinc sulfate $0.8 \mathrm{M}$ in water/methanol $(50 / 50 \mathrm{v} / \mathrm{v}))$ containing I.S. and diluted to a final volume of $1 \mathrm{~mL}$ with water. The 
samples were incubated for $10 \mathrm{~min}$ in a thermoshaker with thorough shaking $\left(1300 \mathrm{rpm}, 4^{\circ} \mathrm{C}\right.$ ) and centrifuged $\left(10 \mathrm{~min}, 16,000 \times \mathrm{rcf}, 4^{\circ} \mathrm{C}\right)$. Supernatants $(700 \mu \mathrm{L})$ were transferred to Oasis HBL SPE cartridges (preconditioned with methanol and water, $1 \mathrm{~mL}$ each). Following one wash with water $(1 \mathrm{~mL})$ and two washes with methanol/water $(1 \mathrm{~mL}, 10 / 90 \mathrm{v} / \mathrm{v})$, the samples were eluted with methanol $(1 \mathrm{~mL})$ and evaporated to dryness. The samples were reconstituted in 25 $\mu \mathrm{L}$ methanol (10 min, $1300 \mathrm{rpm}, 4^{\circ} \mathrm{C}$, thermoshaker) and transferred into new glass vials.

Chromatographic performance: Ten point calibration curves were generated by a zero sample (charcoal treated human plasma/water mixture containing I.S.) and nine calibrators (Supplemental Table S3). To meet requirements of the FDA guidance for industry, the coefficient of determination $\left(R^{2}\right)$ has to be higher than 0.96 and at least $75 \%$ of all calibrators have to be valid (Supplemental Table S3).

Specificity: Blank samples without the addition of analyte and I.S. were processed and injected into the UPLC-MS/MS within an analytical run. The peak areas evaluated in the blank samples were not allowed to exceed $20 \%$ of the mean LLOQ peak area.

Recovery: The absolute recovery was determined by comparing the mean peak areas for extracted with unextracted samples (100\% recovery) at the concentrations of QC high, QC medium, and QC low (Supplemental Table S4).

Limit of detection (LLOD) and limit of quantification (LLOQ): Lower limit of detection (LLOD) and lower limit of quantification (LLOQ) were determined by direct injection of decreasing amounts of analyte and were calculated as the concentration giving peaks with a signal-to-noise ratio of $\geq$ 3 and $\geq 5$, respectively. The LLOQ was decided as the lowest concentration on the calibration curve which fulfilled the criteria of imprecision $\pm 15 \%$, and inaccuracy within $\pm 15 \%$ (Supplemental Table S3).

Reproducibility: Five replicates of QCs at three concentration levels (QC high, QC medium, and QC low) were processed and injected into the UPLC-MS/MS. To ensure the reproducibility, these sets of QCs were tested within validation runs. In each run, intra-run imprecision (\% 
coefficient of variation; CV\%) of each QC series had to be below $15 \%$ (20\% at the LLOQ) and intra-run inaccuracy (\% relative error of measurement; RE\%) had to be within $\pm 15 \%$ of the nominal values ( $\pm 20 \%$ at the LLOQ) (Supplemental Table S5).

Carry-over: To evaluate the carry-over of all analytes and I.S. in each analytical run blank samples were injected immediately after the highest calibrator upper limit of quantification (ULOQ). Mean carry-over in the blank sample following the ULOQ had not to exceed $20 \%$ of the signal of the LLOQ for analyte and 5\% for I.S. 
Supplemental Table S1 Optimized ion source conditions and analytical parameters.

\begin{tabular}{|c|c|c|c|c|c|c|c|c|c|c|c|}
\hline Analyte & 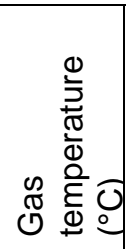 & 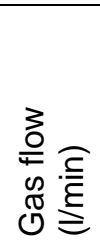 & 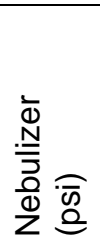 & 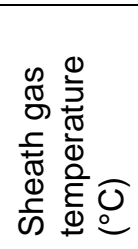 & 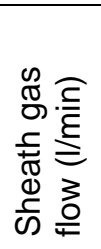 & 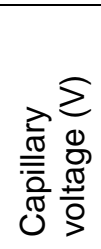 & 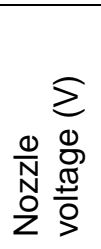 & 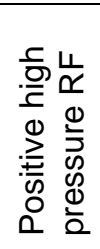 & 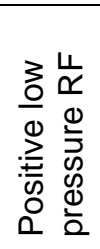 & 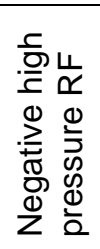 & 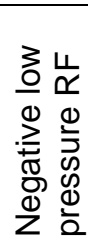 \\
\hline 11-Dehydrocorticosterone & 290 & 14 & 20 & 300 & 11 & 3000 & 1500 & 200 & 110 & 150 & 60 \\
\hline 11-Deoxycorticosterone & 290 & 14 & 20 & 300 & 11 & 3000 & 1500 & 200 & 110 & 150 & 60 \\
\hline 11-Deoxycortisol & 290 & 14 & 20 & 300 & 11 & 3000 & 1500 & 200 & 110 & 150 & 60 \\
\hline 17a-Hydroxyprogesterone & 290 & 14 & 20 & 300 & 11 & 3000 & 1500 & 200 & 110 & 150 & 60 \\
\hline $\begin{array}{l}5 \alpha \text {-Dihydrotestosterone / } \\
5 \alpha \text {-Dihydrotestosterone-d3 }\end{array}$ & 290 & 20 & 15 & 350 & 11 & 3000 & 1500 & 120 & 90 & 150 & 60 \\
\hline $\begin{array}{l}\text { Aldosterone / } \\
\text { Aldosterone-d7 }\end{array}$ & 290 & 14 & 20 & 300 & 11 & 3000 & 1500 & 200 & 110 & 150 & 60 \\
\hline Androstendione / Androstendione-d7 & 290 & 20 & 15 & 350 & 11 & 2000 & 1500 & 170 & 90 & 150 & 60 \\
\hline $\begin{array}{l}\text { Androsterone / } \\
\text { Androsterone-d2 }\end{array}$ & 290 & 20 & 15 & 350 & 11 & 2000 & 1500 & 170 & 90 & 150 & 60 \\
\hline Corticosterone / Corticosterone-d8 & 290 & 14 & 20 & 300 & 11 & 3000 & 1500 & 200 & 110 & 150 & 60 \\
\hline Cortisol & 290 & 14 & 20 & 300 & 11 & 3000 & 1500 & 200 & 110 & 150 & 60 \\
\hline $\begin{array}{l}\text { Cortisone / } \\
\text { Cortisone-d2 }\end{array}$ & 290 & 14 & 20 & 300 & 11 & 3000 & 1500 & 200 & 110 & 150 & 60 \\
\hline Dehydroepiandrosterone & 290 & 14 & 20 & 300 & 11 & 3000 & 1500 & 200 & 110 & 150 & 60 \\
\hline Dehydroepiandrosterone-3-sulfate & 290 & 14 & 20 & 300 & 11 & 3000 & 1500 & 200 & 110 & 150 & 60 \\
\hline Progesterone & 290 & 14 & 20 & 300 & 11 & 3000 & 1500 & 200 & 110 & 150 & 60 \\
\hline $\begin{array}{l}\text { Testosterone / } \\
\text { Testosterone-d2 }\end{array}$ & 290 & 20 & 25 & 350 & 11 & 2500 & 1500 & 170 & 90 & 150 & 60 \\
\hline
\end{tabular}


Supplemental Table S2 Multiple reaction monitoring (MRM) analyte transitions.

\begin{tabular}{|c|c|c|c|c|c|c|c|c|}
\hline Analyte & $\begin{array}{l}\text { 을 } \\
\frac{1}{ \pm} \\
\stackrel{ \pm}{\Sigma}\end{array}$ & 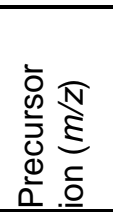 & 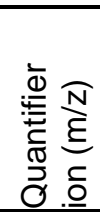 & 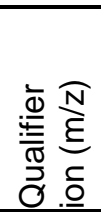 & 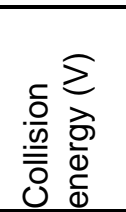 & $\begin{array}{l}\frac{7}{2} \\
\frac{\pi}{0} \\
0\end{array}$ & 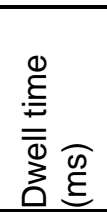 & 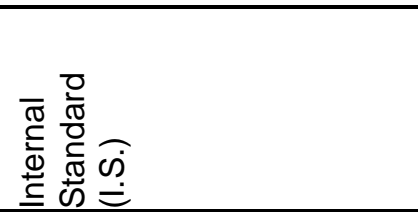 \\
\hline 11-Dehydrocorticosterone & $A$ & 345.2 & 121 & 54.9 & $21 ; 57$ & positive & 100 & Corticosterone-d8 \\
\hline 11-Deoxycorticosterone & $A$ & 331.2 & 97.1 & 109 & $28 ; 25$ & positive & 100 & Corticosterone-d8 \\
\hline 11-Deoxycortisol & $A$ & 347.2 & 97 & 109 & $32 ; 24$ & positive & 100 & Corticosterone-d8 \\
\hline 17a-Hydroxyprogesterone & $\mathrm{A}$ & 331.2 & 97 & 109 & $32 ; 28$ & positive & 100 & Corticosterone-d8 \\
\hline 5a-Dihydrotestosterone & $\mathrm{B}$ & 291.2 & 159 & 255 & $24 ; 12$ & positive & 100 & $5 \alpha$-Dihydrotestosterone-d3 \\
\hline $5 \alpha-D i h y d r o t e s t o s t e r o n e-d 3$ & $\mathrm{~B}$ & 294.3 & 163 & 258 & $24 ; 12$ & positive & 100 & \\
\hline Aldosterone & $\bar{A}$ & 359.2 & 331 & 189 & $17 ; 24$ & negative & 400 & Aldosterone-d7 \\
\hline Aldosterone-d7 & $\mathrm{A}$ & 366.2 & 338 & 196 & $17 ; 24$ & negative & 200 & \\
\hline Androstenedione & $\mathrm{B}$ & 287.2 & 97.1 & 109 & $24 ; 20$ & positive & 100 & Androstenedione-d7 \\
\hline Androstenedione-d7 & $\mathrm{B}$ & 294.3 & 100 & 113 & $24 ; 28$ & positive & 100 & \\
\hline Androsterone & $\mathrm{B}$ & 273.2 & 147 & 255 & $24 ; 12$ & positive & 200 & Androsterone-d2 \\
\hline Androsterone-d2 & $\mathrm{B}$ & 275.2 & 118 & 257 & $52 ; 8$ & positive & 100 & \\
\hline Corticosterone & A & 347.2 & 121 & 329 & $25 ; 9$ & positive & 100 & Corticosterone-d8 \\
\hline Corticosterone-d8 & $\mathrm{A}$ & 355.2 & 125 & 337 & $25 ; 12$ & positive & 100 & \\
\hline Cortisol & $A$ & 363.2 & 121 & 105 & $36 ; 56$ & positive & 100 & Cortisone-d2 \\
\hline Cortisone & $A$ & 361.2 & 121 & 163 & $36 ; 24$ & positive & 100 & Cortisone-d2 \\
\hline Cortisone-d2 & $A$ & 363.2 & 123 & 165 & $36 ; 24$ & positive & 100 & \\
\hline Dehydroepiandrosterone & $A$ & 271.2 & 253 & 213 & $6 ; 12$ & positive & 100 & Androstenedione-d7 \\
\hline Dehydroepiandrosterone-3-sulfate & $A$ & 271.1 & 253 & 213 & $6 ; 10$ & positive & 200 & Corticosterone-d8 \\
\hline Progesterone & A & 315.2 & 109 & 97.1 & $20 ; 24$ & positive & 50 & Corticosterone-d8 \\
\hline Testosterone & $\mathrm{B}$ & 289.2 & 97.1 & 109 & $28 ; 32$ & positive & 50 & Testosterone-d2 \\
\hline Testosterone-d2 & $\mathrm{B}$ & 291.5 & 111 & 125 & $13 ; 24$ & positive & 50 & \\
\hline
\end{tabular}


Supplemental Table S3 Limit of detection (LLOD), lower limit of quantification (LLOQ), signal-tonoise ratio $(\mathrm{S} / \mathrm{N})$, retention time $(\mathrm{RT})$, linearity, and calibration range.

\begin{tabular}{|l|l|l|l|l|l|l|}
\hline Analyte & $\begin{array}{l}\mathrm{LLOD} \\
(\mathrm{nM})\end{array}$ & $\begin{array}{l}\mathrm{LLOQ} \\
(\mathrm{nM})\end{array}$ & $(\mathrm{S} / \mathrm{N})$ & $\begin{array}{l}\mathrm{RT} \\
(\mathrm{min})\end{array}$ & $\begin{array}{l}\text { Linearity } \\
\left(\mathrm{R}^{2}\right)\end{array}$ & $\begin{array}{l}\text { Calibration range } \\
(\mathrm{nM})\end{array}$ \\
\hline 11-Dehydrocorticosterone & 0.49 & 0.98 & 10.5 & 3.1 & 0.998 & $0.98-250$ \\
\hline 11-Deoxycorticosterone & 0.39 & 0.78 & 13.7 & 5.1 & 0.998 & $0.78-200$ \\
\hline 11-Deoxycortisol & 0.39 & 0.78 & 9.9 & 3.73 & 0.992 & $0.78-200$ \\
\hline 17a-Hydroxyprogesterone & 0.39 & 0.78 & 10.5 & 5.59 & 0.998 & $0.78-200$ \\
\hline 5a-Dihydrotestosterone & 0.49 & 0.98 & 60.7 & 11.9 & 0.999 & $0.98-250$ \\
\hline Aldosterone & 0.10 & 0.2 & 12.0 & 1.72 & 0.999 & $0.2-50$ \\
\hline Androstenedione & 0.39 & 0.78 & 13.8 & 8.85 & 0.999 & $0.78-200$ \\
\hline Androsterone & 1.96 & 3.91 & 5.6 & 16.2 & 0.999 & $1.95-500$ \\
\hline Corticosterone & 0.49 & 0.98 & 54.1 & 3.56 & 0.996 & $0.98-250$ \\
\hline Cortisol & 0.98 & 1.95 & 5.7 & 2.29 & 0.991 & $3.91-1000$ \\
\hline Cortisone & 0.98 & 1.95 & 38.0 & 2.24 & 0.994 & $1.95-500$ \\
\hline Dehydroepiandrosterone & 1.96 & 3.91 & 7.3 & 5.37 & 0.999 & $1.95-500$ \\
\hline Dehydroepiandrosterone 3-sulfate & 9.77 & 19.53 & 9.1 & 3.55 & 0.993 & $19.53-5000$ \\
\hline Progesterone & 0.03 & 0.05 & 7.6 & 7.4 & 0.994 & $0.39-100$ \\
\hline Testosterone & 0.20 & 0.39 & 55.3 & 7.6 & 0.999 & $0.39-100$ \\
\hline
\end{tabular}


Supplemental Table S4 Recovery (QC high, QC medium, QC low).

\begin{tabular}{|c|c|c|c|c|c|c|c|c|c|}
\hline & \multicolumn{3}{|c|}{$\begin{array}{l}\text { Nominal } \\
\text { concentration (nM) }\end{array}$} & \multicolumn{3}{|c|}{ Recovery (\%) } & \multicolumn{3}{|c|}{ CV\% } \\
\hline & $\begin{array}{l}\text { QC } \\
\text { high }\end{array}$ & $\begin{array}{l}\text { QC } \\
\text { medium }\end{array}$ & $\begin{array}{l}\text { QC } \\
\text { low }\end{array}$ & $\begin{array}{l}\text { QC } \\
\text { high }\end{array}$ & $\begin{array}{l}\mathrm{QC} \\
\text { medium }\end{array}$ & $\begin{array}{l}\text { QC } \\
\text { low }\end{array}$ & $\begin{array}{l}\text { QC } \\
\text { high }\end{array}$ & $\begin{array}{l}\text { QC } \\
\text { medium }\end{array}$ & $\begin{array}{l}\text { QC } \\
\text { low }\end{array}$ \\
\hline 11-Dehydrocorticosterone & 125 & 31.3 & 2.0 & 114.0 & 103.2 & 95.9 & 3.7 & 2.1 & 2.2 \\
\hline 11-Deoxycorticosterone & 100 & 25.0 & 1.6 & 98.5 & 95.4 & 90.4 & 8.9 & 3.1 & 3.3 \\
\hline 11-Deoxycortisol & 100 & 25.0 & 1.6 & 106.7 & 91.8 & 95.0 & 6.7 & 2.9 & 3.4 \\
\hline $\begin{array}{l}\text { 17a- } \\
\text { Hydroxyprogesterone }\end{array}$ & 100 & 25.0 & 1.6 & 82.7 & 83.5 & 81.8 & 9.3 & 4.4 & 1.4 \\
\hline $5 \alpha$-Dihydrotestosterone & 125 & 31.3 & 2.0 & 88.7 & 120.2 & 96.6 & 20.0 & 15.3 & 13.9 \\
\hline Aldosterone & 25 & 6.3 & 0.4 & 99.2 & 99.1 & 98.3 & 5.2 & 4.6 & 10.3 \\
\hline Androstenedione & 100 & 25.0 & 1.6 & 100.2 & 100.7 & 98.0 & 1.8 & 2.4 & 3.5 \\
\hline Androsterone & 250 & 62.5 & 3.9 & 94.9 & 98.4 & 102.5 & 1.7 & 5.8 & 0.2 \\
\hline Corticosterone & 125 & 31.3 & 2.0 & 111.4 & 98.9 & 95.1 & 5.6 & 2.0 & 2.2 \\
\hline Cortisol & 250 & 62.5 & 3.9 & 108.0 & 102.9 & 97.4 & 3.5 & 4.5 & 2.2 \\
\hline Cortisone & 250 & 62.5 & 3.9 & 100.2 & 104.5 & 98.5 & 4.9 & 5.1 & 1.6 \\
\hline Dehydroepiandrosterone & 250 & 62.5 & 3.9 & 102.1 & 102.7 & 107.8 & 5.4 & 4.3 & 5.7 \\
\hline $\begin{array}{l}\text { Dehydroepiandrosterone- } \\
\text { 3-sulfate }\end{array}$ & 2500 & 625.0 & 39.1 & 88.9 & 103.8 & 96.8 & 5.6 & 4.1 & 2.6 \\
\hline Progesterone & 50 & 12.5 & 0.8 & 80.9 & 92.4 & 98.0 & 11.4 & 6.0 & 0.8 \\
\hline Testosterone & 50 & 12.5 & 0.8 & 101.7 & 103.9 & 100.5 & 3.9 & 1.5 & 2.2 \\
\hline
\end{tabular}


Supplemental Table S5 Reproducibility: Nominal and measured concentration, standard deviation (S.D.), imprecision (CV\%), and inaccuracy (RE\%) of QC high, QC medium, and QC low.

\begin{tabular}{|c|c|c|c|c|c|c|c|c|c|c|c|c|c|c|c|}
\hline \multirow[b]{2}{*}{ Analyte } & \multicolumn{3}{|c|}{$\begin{array}{l}\text { Nominal } \\
\text { concentration }(\mathrm{nM})\end{array}$} & \multicolumn{3}{|c|}{$\begin{array}{l}\text { Measured } \\
\text { concentration (nM) }\end{array}$} & \multicolumn{3}{|l|}{ S.D. } & \multicolumn{3}{|l|}{ CV\% } & \multicolumn{3}{|l|}{ RE\% } \\
\hline & $\begin{array}{l}\text { QC } \\
\text { high }\end{array}$ & $\begin{array}{l}\text { QC } \\
\text { med }\end{array}$ & $\begin{array}{l}\mathrm{QC} \\
\text { low }\end{array}$ & $\begin{array}{l}\text { QC } \\
\text { high }\end{array}$ & $\begin{array}{l}\text { QC } \\
\text { med }\end{array}$ & $\begin{array}{l}\text { QC } \\
\text { low }\end{array}$ & $\begin{array}{l}\text { QC } \\
\text { high }\end{array}$ & $\begin{array}{l}\text { QC } \\
\text { med }\end{array}$ & $\begin{array}{l}\mathrm{QC} \\
\text { low }\end{array}$ & $\begin{array}{l}\text { QC } \\
\text { high }\end{array}$ & $\begin{array}{l}\text { QC } \\
\text { med }\end{array}$ & $\begin{array}{l}\text { QC } \\
\text { low }\end{array}$ & $\begin{array}{l}\text { QC } \\
\text { high }\end{array}$ & $\begin{array}{l}\text { QC } \\
\text { med }\end{array}$ & $\begin{array}{l}\text { QC } \\
\text { low }\end{array}$ \\
\hline 11-Dehydrocorticosterone & 125 & 31.3 & 2.0 & 120.7 & 28.6 & 1.8 & 9.9 & 1.0 & 0.1 & 8.2 & 3.4 & 7.0 & -3.5 & -8.5 & -6.8 \\
\hline 11-Deoxycorticosterone & 100 & 25.0 & 1.6 & 101.6 & 25.3 & 1.7 & 5.3 & 0.6 & 0.1 & 5.2 & 2.2 & 8.2 & 1.6 & 1.1 & 5.8 \\
\hline 11-Deoxycortisol & 100 & 25.0 & 1.6 & 96.5 & 24.2 & 1.5 & 8.1 & 0.5 & 0.1 & 8.4 & 1.9 & 3.6 & -3.5 & -3.2 & -1.8 \\
\hline 17a-Hydroxyprogesterone & 100 & 25.0 & 1.6 & 102.9 & 26.0 & 1.4 & 9.4 & 0.7 & 0.1 & 9.2 & 2.9 & 8.6 & 2.9 & 3.9 & -12.4 \\
\hline 5a-Dihydrotestosterone & 125 & 31.3 & 2.0 & 123.8 & 30.2 & 1.8 & 2.9 & 0.5 & 0.1 & 2.4 & 1.7 & 3.7 & -0.9 & -3.4 & -5.3 \\
\hline Aldosterone & 25 & 6.3 & 0.4 & 23.5 & 5.5 & 0.3 & 1.9 & 0.5 & 0.0 & 8.0 & 8.4 & 10.7 & -6.0 & -11.6 & -13.1 \\
\hline Androstenedione & 100 & 25.0 & 1.6 & 98.9 & 24.3 & 1.4 & 1.7 & 0.9 & 0.0 & 1.7 & 3.7 & 1.0 & -1.1 & -2.8 & -9.7 \\
\hline Androsterone & 250 & 62.5 & 3.9 & 250.8 & 58.9 & 4.1 & 4.5 & 1.0 & 0.1 & 1.8 & 1.7 & 2.3 & 0.3 & -5.8 & 4.5 \\
\hline Corticosterone & 125 & 31.3 & 2.0 & 122.6 & 31.3 & 1.8 & 9.2 & 0.8 & 0.1 & 7.5 & 2.5 & 8.1 & -1.9 & 0.0 & -7.6 \\
\hline Cortisol & 250 & 62.5 & 3.9 & 240.7 & \begin{tabular}{|l|}
63.7 \\
\end{tabular} & 4.5 & 19.1 & 1.1 & 0.3 & 7.9 & 1.7 & 7.7 & $\mid-3.7$ & 2.0 & 13.9 \\
\hline Cortisone & 250 & 62.5 & 3.9 & 243.5 & 63.9 & 3.4 & 11.5 & 2.3 & 0.3 & 4.7 & 3.5 & 9.4 & -2.6 & 2.2 & -13.5 \\
\hline Dehydroepiandrosterone & 250 & 62.5 & 3.9 & 236.6 & 53.5 & 3.7 & 19.3 & 3.0 & 0.4 & 8.2 & 5.7 & 11.4 & \begin{tabular}{|l|}
-5.4 \\
\end{tabular} & -14.3 & \begin{tabular}{|l}
-5.9 \\
\end{tabular} \\
\hline $\begin{array}{l}\text { Dehydroepiandrosterone- } \\
\text { 3-sulfate }\end{array}$ & 2500 & 625.0 & 39.1 & 2643.0 & 685.2 & 42.0 & 5.8 & 38.7 & 6.1 & 0.2 & 5.7 & 14.6 & 5.7 & 9.6 & 7.4 \\
\hline Progesterone & 50 & 12.5 & 0.8 & 49.2 & 11.2 & 0.7 & 3.2 & 0.2 & 0.0 & 6.5 & 2.1 & 4.2 & -1.5 & -10.7 & -11.2 \\
\hline Testosterone & 50 & 12.5 & 0.8 & 43.8 & $\mid 12.3$ & 0.7 & 1.5 & 0.5 & 0.0 & 3.4 & 4.0 & 6.5 & \begin{tabular}{|l|}
-12.3 \\
\end{tabular} & -1.5 & -13.4 \\
\hline
\end{tabular}


A

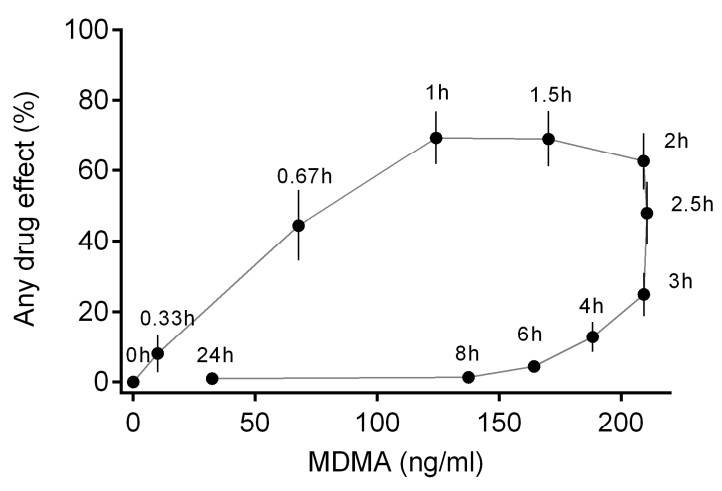

B

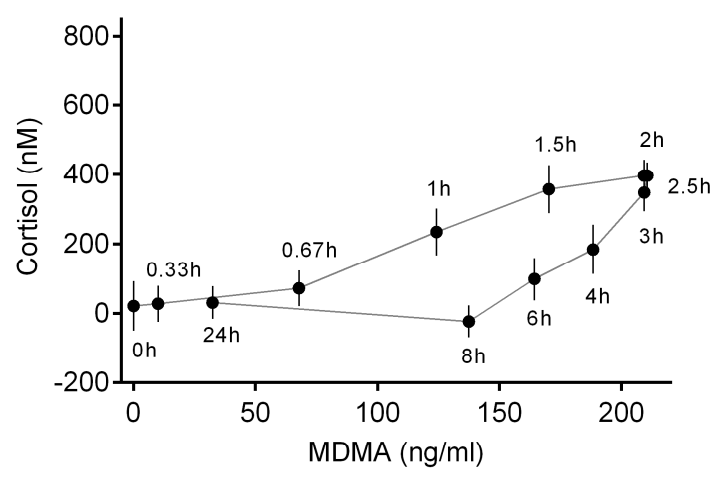

C

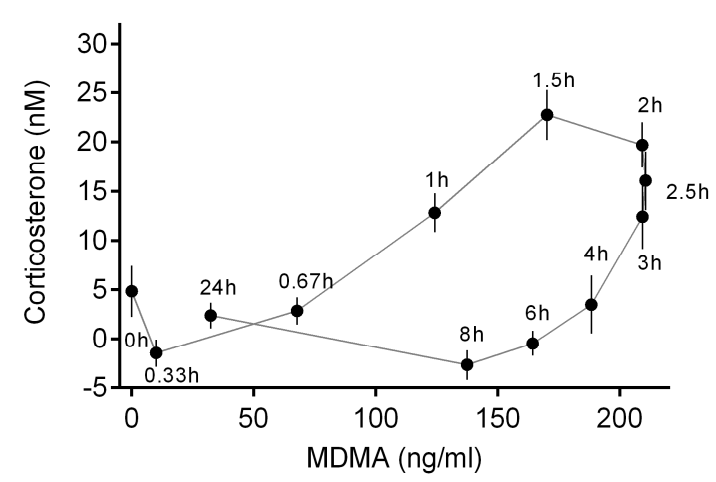

D

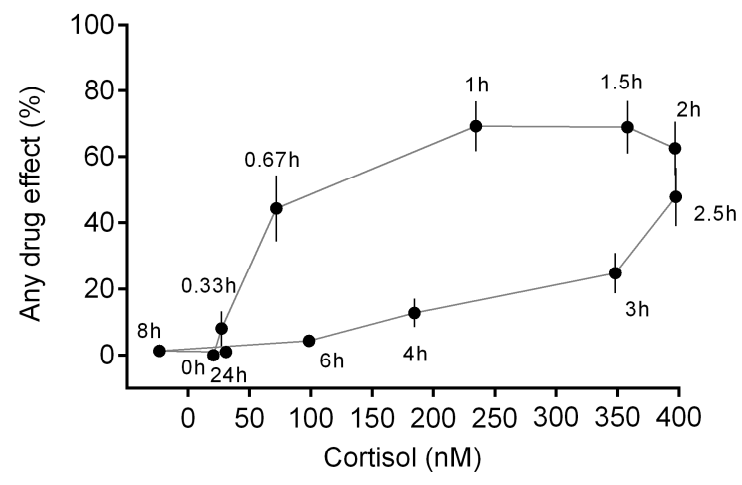

E

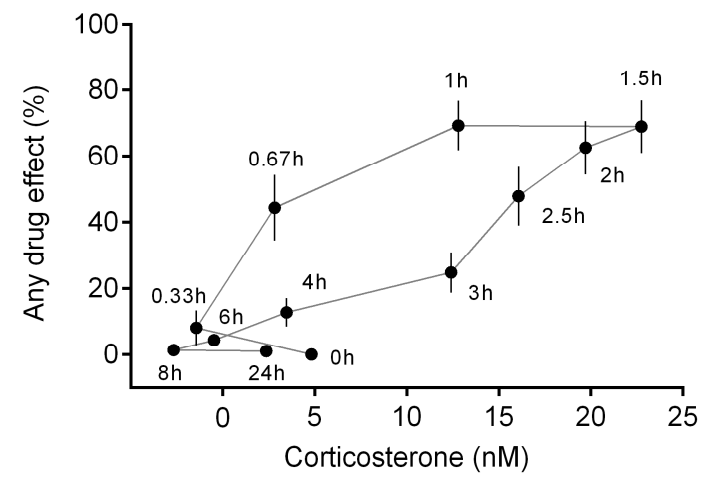

Figure S1 
Supplemental Figure S1 MDMA exposure-response relationship. MDMA responses are shown as MDMA effect (any subjective drug effect, cortisol or corticosterone concentration) minus the individual time-matched effect of placebo. MDMA or placebo was administered at $t$ $=0 \mathrm{~h}$. Subjective responses to MDMA (A) and MDMA-induced changes in cortisol (B) and corticosterone $(\mathrm{C})$ concentrations (mean \pm SEM) of 16 subjects are plotted against mean MDMA plasma concentrations (hysteresis curves). The time of sampling is noted next to each point (in hours after MDMA administration). Clockwise hysteresis was observed for any drug effects $(A)$, cortisol $(B)$, and corticosterone $(C)$ consistent with acute tolerance to the effects of MDMA. After drug administration, the subjective drug effects increased faster and in particular decreased faster than the plasma levels of cortisol (D) or corticosterone (E) over time (clockwise hysteresis). Thus, over time MDMA-induced changes in glucocorticoids do not well reflect the psychotropic effects of the drug in contrast to LSD. 